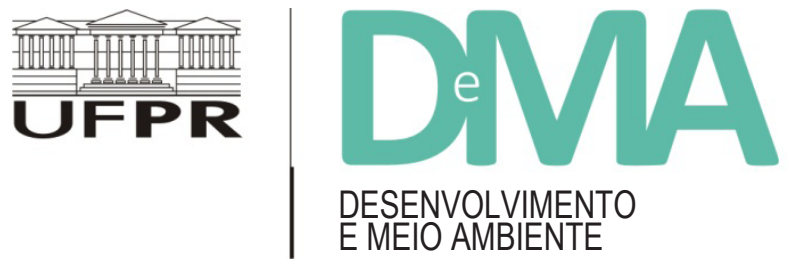

\title{
Paradoxos e ambiguidades na ideia de interdisciplinaridade
}

\author{
Paradoxes and ambiguities in interdisciplinarity
}

\section{Paradoxes et ambiguités de l'idée interdisciplinaire}

\section{Claude RAYNAUT ${ }^{1 *}$}

${ }^{1}$ Antropólogo, foi Diretor de Pesquisa do Centre National de la Recherche Scientifique (CNRS, França) e Diretor do Laboratório de Pesquisa Santé, Sociétés, Développement, Universidade Bordeaux 2. É Doutor Honoris Causa da Universidade Federal do Paraná (UFPR) e conferencista da Escola de Altos Estudos da Coordenação de Aperfeiçoamento de Pessoal de Nível Superior (CAPES).

*E-mail de contato: clauderaynaut@hotmail.com

RESUMO: A prática da interdisciplinaridade nos coloca diante de um paradoxo: embora a ideia que a inspira ainda nos pareça pioneira, ela não tem nada de efetivamente novo. Apareceu há quase um século e desde então nunca deixou de ser aprofundada e aplicada em vários contextos da pesquisa e do ensino. No entanto, apesar de seu aparente sucesso, o projeto de ultrapassagem do quadro disciplinar continua a ser objeto de múltiplas controvérsias e resistências. Quais as razões das dificuldades que essa visão inovadora da prática científica encontra para alcançar um pleno reconhecimento no quadro acadêmico? Em primeiro lugar, há de constatarmos que, como qualquer outra forma de inovação, ela é percebida como ameaça por instituições e atores sociais que se beneficiam da estabilidade de quadros organizacionais estabelecidos e que impõem resistências a toda perspectiva de mudança. Contudo, além dessa blocagem de cunho político - no sentido amplo da palavra - existem também razões mais essenciais, de caráter conceitual e epistemológico, ligadas à confusão que geram a multiplicidade e a heterogeneidade das interpretações da noção e dos conteúdos a ela atribuídos. É esse caráter heterogêneo do pensamento interdisciplinar que gostaria de explorar aqui. Para isso, proponho que, em um primeiro momento, nós nos interroguemos sobre a própria noção de disciplina e sobre a dinâmica de redefinições, de trocas de conceitos e métodos, de passagem de fronteiras, intrínseca ao recorte disciplinar. O primeiro passo para clarificar a ideia interdisciplinar consiste em abster-se de confundi-la com esse movimento constitutivo da vida das disciplinas. Em segundo lugar, se o projeto interdisciplinar se define como esforço para ultrapassar essa dinâmica espontânea das disciplinas e construir algo novo no domínio da produção e da transmissão do conhecimento, quais as características e os objetivos dessa tentativa original para 
dar conta da complexidade e da hibridização do mundo real? Aqui diversas são as metas almejadas, múltiplos os caminhos seguidos e dispares os públicos visados pelos projetos que se reclamam da interdisciplinaridade. Tal diversidade não é um problema em si. Entretanto, torna-se problemática quando a confusão reina, bem como as nuanças e divergências não são suficientemente explicitadas, clarificadas, articuladas. Nesse caso, surge uma incoerência que prejudica a elaboração de uma estratégia institucional comum necessária para combater as falsas interpretações, os preconceitos, as resistências que até hoje impedem que a abordagem seja integrada de modo duradouro e incontestável nas instituições científicas acadêmicas. É esse trabalho de identificação e clarificação da diversidade e das ambiguidades da interpretação da prática interdisciplinar que procurei iniciar nesse texto.

Palavras-chave: história das ciências; disciplinas científicas; interdisciplinaridade; ensino superior; pesquisa.

ABSTRACT: The practice of interdisciplinarity places us before a paradox: although the idea that inspires it still seems to us innovative, it has nothing really new. It appeared almost a century ago and since then has never ceased to be deepened, debated and applied in various contexts of research and teaching. However, despite its apparent success, the project of overcoming the disciplinary framework continues to be the subject of multiple controversies and resistances. What are the reasons for the difficulties that this innovative vision of scientific practice encounters in order to achieve full recognition in the academic field? In the first place, it should be noted that, like any other form of innovation, it is perceived as a threat by institutions and social actors that benefit from the stability of established organizational frameworks and that, therefore, resist any prospect of change. But beyond this political blockade - in the broad sense of the word - there are also more essential reasons, of a conceptual and epistemological character. Such reasons are linked to the confusion generated by the multiplicity and the heterogeneity of the interpretations of the notion and the contents attributed to it. It is this heterogeneous character of interdisciplinary thinking that I would like to explore here. To that end, I propose that, at first, we ask ourselves about the very notion of discipline and about the dynamics of redefinitions, of exchanges of concepts and methods, and of crossing borders, which are intrinsic to the disciplinary division. The first step in clarifying the interdisciplinary idea is to refrain from confusing it with this constitutive movement that has long accompanied the life of the disciplines. Second, if the interdisciplinary project is defined as an effort to overcome this spontaneous dynamic of the disciplines and build something new in the field of knowledge production and transmission, what are the characteristics and objectives of this original attempt to account for the complexity and hybrid nature of the contemporary world? Here, several goals are aimed at, multiple paths are followed and disparate audiences are targeted by projects that claim interdisciplinarity. Such diversity is not a problem in itself. But it becomes problematic when confusion reigns and the nuances and divergences are not sufficiently explicit, clarified and articulated. In this case, there is an incoherence that hampers the elaboration of a common institutional strategy necessary to combat misinterpretations, prejudices, and resistances that have hitherto prevented the approach from being integrated in a lasting and unchallenged way in academic scientific institutions. It is this work of identification and clarification of the diversity and ambiguities of interpretation of the interdisciplinary approach that I tried to initiate in this text.

Keywords: history of science; scientific disciplines; interdisciplinarity; higher education; research.

RÉSUMÉ: La pratique interdisciplinaire nous place devant un paradoxe : bien que l'idée qui l'inspire nous paraisse toujours pionnière, elle n'a rien de réellement neuf. Elle a fat son apparition il y a près d'un siècle et, depuis, n'a cessé d'être approfondie, débattue et mise en application dans divers contextes de recherche et d'enseignement. Cependant, malgré son apparent succès, le projet de dépasser le découpage disciplinaire demeure l'objet de multiples controverses et résistances. Quelles sont les raisons des difficultés que 
rencontre cette vision innovante de la pratique scientifique pour atteindre une pleine reconnaissance dans le cadre académique? En premier lieu, nous devons constater que, de même que n'importe quelle autre forme d'innovation, elle est perçue comme une menace par les institutions et les acteurs sociaux qui tirent parti de la stabilité de cadres d'organisation bien établis et qui opposent résistance à toute perspective de changement. Mais, au-delà de ce blocage de caractère politique - au sens large du terme - il y a également des raisons plus essentielles, de nature conceptuelle et épistémologique. Des raisons liées à la confusion que génèrent la multiplicité et l'hétérogénéité des interprétations de la notion d'interdisciplinarité et des contenus qui lui sont attribués. C'est ce caractère hétérogène de la pensée interdisciplinaire que je voudrais explorer ici. Pour cela, je propose que nous nous interrogions, dans un premier temps, sur la notion même de discipline et sur la dynamique de redéfinitions, d'échanges de concepts et de méthodes, de franchissement de frontières, qui est intrinsèque au découpage disciplinaire. Le premier pas en vue de clarifier l'idée interdisciplinaire consiste à s'abstenir de la confondre avec ce mouvement spontané qui accompagne depuis longtemps la vie des disciplines. En second lieu, si le projet interdisciplinaire se définit comme un effort pour dépasser cette dynamique spontanée des disciplines et construire du nouveau dans le domaine de la production et de la transmission de la connaissance, quelles sont les caractéristiques et les objectifs de cette tentative originale pour rendre compte de la complexité et du caractère hybride du monde contemporain ? Ici, divers sont les buts visés, multiples les chemins suivis et distincts les publics visés par les projets qui se réclament de l'interdisciplinarité. Une telle diversité n'est pas un problème en soi. Mais elle en devient un quand la confusion règne et que les nuances et divergences ne sont pas suffisamment explicitées, clarifiées et articulées. Dans ce cas, nait une incohérence qui fait obstacle à l'élaboration d'une stratégie institutionnelle commune nécessaire pour combattre les fausses interprétations, les préjugés, les résistances qui, jusqu'à présent, empêchent que cette démarche soit intégrée de façon durable et incontestable dans les institutions scientifiques académiques. C'est ce travail d'identification et de clarification de la diversité et des ambigüités d'interprétation de la démarche interdisciplinaire que j'ai voulu entamer dans ce texte.

Most-clé: histoire des sciences; disciplines scientifiques; interdisciplinarité; enseignement supérieur; recherche.

A prática da interdisciplinaridade no ensino e na pesquisa nos coloca diante de um paradoxo: ainda que a ideia nos pareça pioneira, ela não tem nada de efetivamente novo. Desde o final dos anos 1930, o termo é utilizado nos estudos sobre educação e seu emprego torna-se frequente a ponto de ser incluído no suplemento do Oxford English Dictionnary (Klein, 1996, p. 9). Durante várias décadas, essa noção continua a avançar discretamente nas "shadows structures" da instituição universitária (Klein, 1996, p. 3) para se manifestar, no final dos anos 1960 , como uma ideia diretriz na reforma de muitas universidades e centros de pesquisa em praticamente todo o mundo, com o objetivo de propiciar melhor colaboração entre disciplinas científicas até então pouco relacionadas entre si. Esse processo ocorreu especialmente na França, com o reagrupamento das antigas faculdades especializadas em universidades pluridisciplinares. Entretanto, a mesma preocupação também se deu em escala internacional, uma vez que, desde 1972, a Organisation de Coopération et de Développement Économiques já publicava um relatório sobre esse tema (Apostel, 1972).

Em 1979, nos EUA, esse projeto era compartilhado por um número bastante expressivo de intelectuais e pesquisadores, o que os levou a se reunirem e criarem a Association for Integrative Studies, uma associação profissional destinada a oferecer um espaço de encontro e uma tribuna para 
os pensadores engajados na reflexão e na ação voltadas para a ultrapassagem das barreiras disciplinares. No mesmo período, na França, os poderes públicos lançavam, por intermédio da Délégation à la Recherche Scientifique et Technique (DGRST), diversas incitativas que visavam a estimular a aproximação de várias disciplinas científicas ao redor de temas de pesquisa voltados para problemas de interesse geral. Durante as últimas décadas do século XX, formações universitárias de caráter interdisciplinar começam a surgir em diferentes países. Embora isso tenha ocorrido especialmente nos Estados Unidos, o Brasil foi igualmente percursor nesse domínio, não apenas devido à criação de diversos diplomas universitários - por exemplo, o MADE da UFPR em 1993 -, mas sobretudo por se dotar de um quadro institucional nacional de acompanhamento e apoio a esse movimento. De fato, em 1999, a CAPES criava uma comissão especialmente incumbida de avaliar tais diplomas, cuja avaliação não poderia ser feita com as ferramentas habituais de análise. Essa comissão se transformou, aproximadamente dez anos mais tarde, na Coordenação da Área Interdisciplinar que, desde então, desempenha um papel ativo na promoção da prática interdisciplinar nas universidades do país. O sucesso desse esforço foi tal que se contam hoje mais de 250 cursos universitários interdisciplinares no Brasil.

Essa mobilização, voltada para a renovação do ensino e da pesquisa além das fronteiras disciplinares, foi acompanhada de um esforço significativo de reflexão teórica e metodológica. Isso se traduziu, especialmente desde o início dos anos 1990, em um aumento de publicações dedicadas ao tema ${ }^{1}$. Para nos deter às mais recentes, destacaremos a obra pedagógica publicada por Repko, em 2008; já em 2010, merece atenção um Manual da Interdisciplinaridade, publicada pela Editora Universitária de Oxford (Frodeman et al., 2010) e uma obra coletiva sobre a renovação da abordagem interdisciplinar (Origgi \& Darbellay, 2008). No Brasil, com o apoio da CAPES, 2011, 2015 e 2017 foram marcados pelo aparecimento de três obras maiores consagradas aos aspectos teóricos e práticos da interdisciplinaridade, tendo como base exemplos locais e internacionais (Philippi \& Silva Neto, 2011; Philippi \& Fernandes, 2015).

Atualmente, não há ao certo uma palavra utilizada com mais frequência nas discussões sobre a inovação na formação e na pesquisa que "interdisciplinaridade". O termo tornou-se praticamente uma referência obrigatória nos projetos pedagógicos que almejam destacar seu caráter inovador. A tal ponto que puderam se referir ao conceito como o "buzzword of the moment" (Klein, 1996, p. 9). O paradoxo é que, apesar desse aparente sucesso, após mais de meio século de reflexão e de prática, esse projeto de ultrapassagem do quadro disciplinar continua a ser objeto de múltiplos debates e controvérsias. Desde 1990, Dogan \& Pahre propõem que o uso do termo "interdisciplinaridade" seja banido, por conta da ausência de um real significado (apud Klein, 1996, p. 10). Até hoje, as resistências são múltiplas. Os diplomas interdisciplinares muitas vezes penam para se beneficiarem de um pleno reconhecimento científico e estatutário nas universidades, em que a separação por disciplinas continua a reinar na definição dos programas, na atribuição dos recursos

\footnotetext{
${ }^{1}$ Ver, por exemplo, a abundante bibliografia proposta por Repko (2008).
} 
e na gestão de carreira dos professores. Em 2010, S. Fuller, um universitário que há muito tempo tomava parte na reflexão crítica sobre as disciplinas, constatava a contradição existente entre a estratégia de desenvolvimento das universidades e a possibilidade dos professores de terem um cargo fora dos departamentos disciplinares (Fuller, 2010). Em um plano mais fundamental, outro autor colocava em dúvida a própria pertinência da noção de interdisciplinaridade enquanto procedimento intelectual. A ela, prefere o caminho que segue o especialista, quando ele é solidamente enraizado em sua especialidade disciplinar, mas, pela qualidade de seus talentos e por seu inconformismo, mostra-se capaz de aplicar suas competências em várias direções e a um leque de assuntos que não são tradicionalmente de sua área (Hacking, 2010). Após mais de meio século de pensamento científico, ao longo do qual, entretanto, ocorreram tantas revoluções conceituais, a interdisciplinaridade não conseguiu ainda conquistar uma posição intelectual e institucional sólida nem a se apresentar de forma incontestável como uma das respostas incontornáveis aos desafios a que são confrontados atualmente a produção e a transmissão de conhecimento.

As causas desse atraso são diversas. Os jogos de interesse e de poder, que toda inovação intelectual desencadeia quando ameaça territórios institucionais estabelecidos há muito tempo, desempenharam, sem dúvida, um papel significativo nessa situação. No entanto, parece existir, ao meu ver, uma causa mais substancial e mais profunda, atrelada ao modo como a própria ideia de interdisciplinaridade foi trabalhada e construída. Um percurso pela literatura faz rapidamente saltar aos olhos que o mesmo termo é utilizado para designar uma multiplicidade de visões diferentes, sendo muitas divergentes entre si.
Os projetos intelectuais ou pedagógicos unidos sob essa mesma bandeira têm pontos de partida epistemológicos muito díspares; eles não se voltam para os mesmos objetivos nem preconizam os mesmos métodos de trabalho. A diversidade das abordagens não é, em si, um problema, se ela for explicitada e tratada com clareza. Infelizmente, porém, as posições adotadas são muitas vezes doutrinárias; elas ignoram ou depreciam as concepções que delas se diferenciam. Essa confusão gera uma deficiência em dois sentidos.

Por um lado, a noção se torna mais frágil e mais exposta a críticas na medida em que suas contradições internas e as divergências encontradas nas suas formas de aplicação impedem de responder às contestações de modo construtivo e coerente. Segundo o ângulo do qual parte o questionamento e segundo seu alvo, é possível tanto criticar a ideia de interdisciplinaridade, por pregar um desconstrutivismo pós-moderno que torna subjetiva a busca pela racionalidade, como acusá-la de conduzir à instrumentalização do pensamento científico que o subordina a interesses que lhe são externos. Ou ainda pode-se ver nela nada mais do que um novo desdobramento de um antigo projeto de unificação da ciência. E cada flecha poderá atingir seu alvo entre as diferentes facetas do pensamento interdisciplinar, sob o risco de desacreditar ao mesmo tempo todas as outras interpretações que são dadas ao termo. Por outro, a heterogeneidade dos projetos intelectuais e pedagógicos que se rotulam como interdisciplinares - tendo muitas vezes como único ponto comum o fato de relacionar várias especialidades científicas - configura-se como um "freio" para sua inserção institucional. Com pressupostos teóricos distintos, objetivos discordantes, públicos-alvo diferentes, sua imagem torna-se confusa. Esses projetos diversos 
custam a se inserir em quadros institucionais comuns, tais como os departamentos universitários, e não conseguem responder aos mesmos critérios de avaliação. Inovar em relação às formas institucionais que foram criadas há muito tempo em função da grade de disciplinas implica a aplicação de estratégias coerentes e afinadas. Isso é difícil não porque os atores têm pontos de vista distintos, mas sobretudo porque eles não se dão ao trabalho de explicitar suas diferenças e as aceitar a fim de poder pensar sobre seu posicionamento mútuo e identificar os possíveis pontos de articulação que lhes permitiriam criar um fronte de batalha comum.

É esse caráter heterogêneo do pensamento interdisciplinar que gostaria de explorar aqui, pois me parece ser o primeiro passo indispensável de um percurso intelectual cujo propósito é se desfazer das imprecisões conceituais atuais. Reconhecer e considerar as diferenças, como também não confundir indistintamente todas as formas de troca e de relações entre disciplinas em uma acepção confusa de interdisciplinaridade é, ao meu ver, a primeira etapa indispensável de uma estratégia destinada a restaurar uma imagem legível e coerente das novas perspectivas científicas inauguradas por esse projeto intelectual, nas diferentes formas que ele pode assumir. Para isso, proponho que, em um primeiro momento, nós nos interroguemos sobre a própria noção de disciplina e sobre a dinâmica de redefinições, de trocas, de passagem de fronteiras que lhe é intrínseca. Examinaremos, em seguida, diferentes formas de uma interdisciplinaridade que não se confunde com esse movimento espontâneo que acompanha há muito a vida das disciplinas como manifestação da liberdade de todo pensamento humano. Uma busca pela interdisciplinaridade que represente um esforço inovador, deliberado e orga- nizado para responder à complexidade e ao caráter híbrido da realidade contemporânea por meio de uma articulação metódica dos múltiplos olhares que a ciência pode portar sobre ela mesma.

\section{As disciplinas: uma história movimentada, uma dinâmica constante}

A partir do momento em que empregamos as noções de inter, de multi ou de transdisciplinaridade, mobilizamos, ao mesmo tempo, a noção de disciplina. Esse termo se tornou tão banal, com uso tão frequente no campo do ensino tanto pré-universitário quanto universitário, que seu conteúdo parece ser óbvio, como um fato que se impõe com a força da evidência, como uma ordem que extrai sua legitimidade da própria diversidade dos objetos e dos questionamentos que se colocam diante do espírito humano para serem conhecidos e pensados.

Um rápido olhar sobre a história da ciência ocidental mostra, entretanto, que a realidade é bastante diferente. Como vários autores nos lembram, o recorte das fronteiras das disciplinas enquanto domínios de ensino e de pesquisa, como o conhecemos atualmente, é produto de uma história social (Repko, 2008; Klein, 1996). Uma história marcada, num primeiro momento, pela progressiva laicização das sociedades europeias e pela lenta emancipação da busca por conhecimento em relação aos dogmas religiosos e caracterizada, em seguida, por uma articulação crescente entre a ciência e a técnica, em busca de objetivos induzidos pela sociedade. A ideologia do progresso, fio condutor da revolução industrial do século XIX, fazia da ciência e de suas aplicações o fundamento de melhorias para a condição humana. Rapidamente, as descobertas 
científicas e as inovações tecnológicas se impuseram também como armas poderosas ao serviço de estratégias de dominação econômica, política e militar. Ao longo desse processo histórico, que se iniciou há mais de duzentos anos, a lógica que inspirava a divisão do campo de conhecimento em domínios distintos não parou de evoluir, a nomenclatura e as identidades disciplinares passaram por uma constante evolução e sua inserção no campo institucional e social se diversificou.

O ensino, no modo como era praticado na universidade na Idade Média, especialmente após Thomás de Aquino, era entendido como um caminho construído e ponderado rumo a uma compreensão mística do mundo (Panofsky, 1975 p. 89 et $s q$ ). A aplicação do método escolástico, apoiado na herança do pensamento da Antiguidade, permitia aprofundar a compreensão da verdade que os textos sagrados, muitas vezes de forma velada, transmitiam. Esse encaminhamento passava pela aquisição de competências na formação e expressão do pensamento: gramática, dialética e retórica (agrupadas sob a denominação de Trivium). Passava também pelo domínio da aritmética e da geometria, entendidas como ferramentas de pensamento capazes de submeter a observação do mundo ao procedimento da medição, aprendizagens as quais se conciliavam com a exploração de dois domínios da experiência em que se impõe de forma mais evidente o reino dos números: a astronomia e a música (essas quatro últimas matérias eram agrupadas sob a denominação de Quadrivium). O conjunto dessas competências formava as "Artes Liberais" e abria caminhos rumo à Sabedoria. Seu ensino se configurava como a vocação superior da Universidade.
A existência de conhecimentos práticos e de savoir-faire era igualmente reconhecida: medicina, botânica, arquitetura e agricultura. Porém, essas "Artes mecânicas" (mesmo quando eram responsáveis pela reputação de universidades como Padoue, Salerne ou Montpellier, célebres por seu ensino de Medicina) vinham em segundo plano e se legitimavam intelectualmente de acordo com a contribuição que podiam oferecer ao esforço mais geral de compreensão conduzido pelas artes liberais. O universo do conhecimento, por mais dividido que seja em campos diferenciados, era então percebido como uma paisagem coerente organizada de modo hierárquico em função de uma finalidade comum: a mobilização dos recursos do cérebro humano a serviço da compreensão e glorificação da obra divina. É significativo, a esse respeito, que a referência à constelação dos saberes tenha constituído um motivo recorrente na ornamentação dos edifícios religiosos góticos. Um exemplo claro dessa presença é o Campanário do Duomo de Florença, construído no século XIV, iniciado por Giotto e continuado após sua morte, decorado por aproximadamente cinquenta quadros esculpidos, que se constitui como uma enciclopédia que representa a história do homem desde a criação e detalha o conjunto das atividades humanas, intelectuais e práticas, como tantas etapas na via da espiritualidade e da salvação eterna ${ }^{2}$.

Com a revolução conceitual do Renascimento, a realidade empírica começa a se libertar do estatuto que lhe era conferido durante toda a Idade Média, ou seja, uma compilação de signos que somente merecia nossa atenção se procurássemos decifrar o poder divino de que eram manifestação (Duby, 1976; Grabar, 1992). Com os progressos técnicos da

\footnotetext{
${ }^{2}$ Os originais desses quadros estão expostos no museu da Ópera del Duomo, em Florença.
} 
navegação, a exploração do planeta, conduzida inicialmente por objetivos exclusivamente comerciais, mas posteriormente inspirada de mais em mais no apetite de conhecimento, defronta a uma multiplicidade de fatos naturais e humanos absolutamente novos um saber estabelecido, firmemente arraigado até então, no corpus de conhecimentos herdados da Antiguidade e na revelação de textos sagrados. Tornou-se desde então imperativo descrever esses fatos, classificá-los e relacioná-los entre si para tentar compreender uma diversidade do mundo à qual os espíritos não estavam preparados. Simultaneamente, o progresso da ótica e da observação do céu explodiam o modelo geocêntrico dominante até então na concepção cosmográfica do universo. Assim, todos os antigos moldes de pensamento do mundo deveriam ser reconstruídos. Transformada em um campo de questionamentos não resolvidos e não mais em um texto a decifrar para confirmar certezas fundadas na fé, essa nova realidade merecia dali em diante que the consagrassem energia para observar, ordenar, identificar as leis próprias às quais ela obedece.

Essa mudança radical de paradigma, apesar de ter partido de uma ruptura primeira que caracteriza o Renascimento, apenas ganhou espaço de forma progressiva na sociedade europeia. A Igreja continuou por muito tempo a dominar o sistema de pensamento e as instituições de transmissão de saber, especialmente as universidades. No final do século XVI, Francis Bacon, considerado um dos fundadores do pensamento científico moderno, inclusive por seu esforço para estabelecer um repertório ponderado dos domínios do conhecimento, continuava a colocar a filosofia e a teologia, enquanto reflexão sobre as causas últimas, no topo de uma hierarquia na qual a história natural - recense- amento e descrição das coisas da natureza - não era, finalmente, mais do que uma preliminar a uma busca de sentido mais fundamental (Weingart, 2010). Foi em 1633, em plena era dita "clássica", que Galileu foi condenado pelo Santo Ofício por suas teses cosmográficas contrárias à doutrina da Igreja. Foi preciso aguardar ainda mais de um século para que, com a Enciclopédia coordenada por Diderot e D'Alembert, o esforço do espírito humano para descrever o mundo se libertasse da tutela da teologia e da supremacia da filosofia (Durel, 2003). Muitas décadas e uma revolução foram ainda necessárias na França para que, no começo do século XIX, o físico e astrônomo Laplace pudesse responder, sem correr riscos, a Napoleão, que o interrogava sobre o lugar de Deus em seu sistema explicativo: "Não preciso dessa hipótese".

A exploração científica do mundo passou então a ser conduzida apenas pelos princípios da razão. Fundada na dúvida, libertou-se de respostas a priori impostas por dogmas. Não tinha mais que se colocar a serviço de uma reflexão sobre as causas primeiras. Livra-se, assim, da exigência de fazer convergir as interrogações sobre o mundo empírico em uma finalidade comum: a decifração de um grande propósito que daria à natureza sua coerência. $\mathrm{O}$ exercício do pensamento e o ensino do saber não tiveram mais que se estruturar em torno das diferentes "vias" do conhecimento e da sabedoria. Tornaram-se livres para tomar o real como único objeto e para adotar diante dele uma abordagem analítica, fragmentando-o em territórios de observação distintos que constituíam, por sua vez, vários temas de estudo legítimos.

É apenas de forma bem progressiva e tardia que essa evolução dos quadros conceituais, a partir dos quais se estruturava o olhar sobre o mundo, 
passou a refletir nas instituições. Durante todo o século XVIII, as instituições científicas predominantes foram as Academias Reais, em que convergia o conjunto da produção do saber. Elas reuniam competências variadas e abordavam coletivamente temas científicos dos mais diversos. Porém, com esse tipo de funcionamento, elas tiveram de mais em mais dificuldades de se adaptar à multiplicação de objetos de conhecimento e de assuntos trabalhados, diversidade que exigia competências cada vez mais aprofundadas e especializadas (Weingart, 2010).

A resposta a essa necessidade de especialização se deu pelo viés da criação de comunidades científicas que compartilhavam os mesmos interesses. Seus membros se dirigiam prioritariamente uns aos outros, referindo-se a um corpus comum de conhecimentos e empregando uma linguagem cada vez mais especializada. Essas comunidades formaram as Sociedades ou Associações científicas especializadas, o que garantia a divulgação e a circulação de conhecimentos por meio de publicações temáticas cuja difusão se centrava nos membros de cada comunidade.

"Previously, throughout the eighteenth century, books, articles, and even experiments were still addressed to the general public. The more specialized communication among scholars became, the more it was addressed to themselves. This 'closure' of disciplinary communication communities was expressed through specialized journals and in the organization of scholarly associations" (Weingart, 2010, p. 6).
Foi somente com atraso que as universidades se adaptaram ao novo cenário da ciência, à nova separação dos conhecimentos que se dava. O movimento ocorreu em ritmos e formas diferentes de acordo com o país, em função de situações políticas e sociais particulares. Na França, por exemplo, a Revolução fez tábula rasa das antigas universidades, consideradas tacanhamente submissas ao poder da Igreja. Ao longo de todo o XIX, entre sobressaltos históricos e mudanças do sistema político, reformas, dissoluções e recomposições se sucederam: o ensino superior se desdobrou em uma constelação de grandes escolas profissionais (Polytechnique, École Centrale etc.) e de faculdades, dentre as quais algumas tinham uma visada profissional (Medicina, Direito...) e outras respondiam a uma ampla categorização dos campos de conhecimento (Letras, Ciências, depois Economia e Ciências Sociais). Mesmo as regras para atribuição dos diplomas sendo, em grande parte, fixadas pelo Estado, o conteúdo de ensino era determinado, com muita autonomia, pelas faculdades e seus professores. A cátedra, com seu professor titular, constituía o eixo ao redor do qual se estruturava localmente a identidade disciplinar - recorte profundamente marcado, segundo à própria etimologia do termo "disciplina", pela relação singular que se estabelece entre o mestre e seus discípulos. Simultaneamente, as estruturas transversais, tanto as públicas, como os comitês nacionais de avaliação e validação dos diplomas e da gestão da carreira dos docentes, quanto as privadas, como as Sociétés Savantes ${ }^{3}$ ou os comitês editoriais das revistas científicas,

\footnotetext{
${ }^{3}$ Em vários países europeus, durante o século XIX, multiplicaram-se associações de cientistas e eruditos (“Sociétés savantes”, na França; “Learned Societies", na Inglaterra) organizadas conforme campos científicos especializados e reunindo cientistas e pessoas eruditas da sociedade civil para compartilhar e divulgar os resultados de suas pesquisas. Muitas dessas sociedades formaram redes internacionais que, até hoje, constituem um dos quadros mais ativos da circulação das ideias científicas.
} 
ajudaram a inscrever o processo de construção das identidades disciplinares em uma rede mais ampla. Essa transversalidade atingia às vezes uma dimensão internacional, no caso das Sociétés Savantes, e conferia à nomenclatura dos saberes em processo de lapidação argumentos de legitimidade e de universalidade que a relação singular entre o mestre e seus discípulos era incapaz de fornecer.

As condições de implantação das estruturas do ensino superior foram distintas de um país a outro devido à história própria de cada um. É o que atualmente evidenciam as discordâncias na nomenclatura das disciplinas que observamos entre instituições acadêmicas de diversos países. Isso ocorre, por exemplo, quando comparamos os comitês e as seções de avaliação do Conseil National des Universités, na França, com as comissões da CAPES no Brasil ou com as seções da National Science Foundation, nos EUA. Todavia, o que há de comum a todas as situações particulares observadas aqui e acolá é o fato de que o recorte institucional dos campos de saber, ou seja, o leque de disciplinas diante do qual deve se situar o estudante, o professor ou o pesquisador, não é um mero reflexo da heterogeneidade do real e das questões que sua análise desencadeia (mesmo se esses elementos devam também dar conta dessa heterogeneidade). É principalmente o produto de uma construção social, relativa a um contexto social, político e econômico.

As disciplinas científicas são, portanto, muito mais do que um artifício epistemológico destinado a reduzir a complexidade do real, desmembrando-o em facetas que podem assim serem examinadas individualmente, com o auxílio de uma ferramenta conceitual apropriada a cada uma delas. Elas também são componentes do campo social que se estruturou ao longo da emergência da sociedade ocidental moderna, ao redor de uma função especializada: a produção e a transmissão de um saber científico independente da esfera religiosa. Cada um desses componentes assume a forma de uma comunidade social cujos membros estabelecem relações marcadas tanto pela troca e solidariedade quanto pela concorrência entre si. Cada disciplina se inscreve e perdura no âmago das instituições de ensino e pesquisa públicas ou privadas, que se articulam tendo em vista os contextos nacionais e em conformidade com as circunstâncias particulares de cada um deles (Weingart, 2010, p. 6). Ela se torna, ao mesmo tempo, entidade institucional e território social organizado em função de códigos que lhe são próprios, preocupados em proteger suas fronteiras e em defender seus interesses tanto simbólicos quanto materiais e econômicos - teatro de estratégias individuais e coletivas (Becher \& Trowler, 1989).

Ao longo do movimento histórico em que foram construídos e estruturados os estabelecimentos de ensino superior, esses territórios se traduziram institucionalmente, e em termos administrativos, em unidades de ensino, em departamentos, em laboratórios de pesquisa. Sob formas e em níveis diferentes, de acordo com o país e em função do papel mais ou menos predominante desempenhado pelo Estado na organização acadêmica, o pertencimento a uma disciplina e a conformidade com que fundamenta sua singularidade conceitual e metodológica se tornou o primeiro critério no processo de seleção e avaliação dos cursos, bem como na evolução dos recursos para a pesquisa. Esse referencial disciplinar desempenha também um papel predominante na gestão de carreiras individuais dos docentes, na atribuição de diplomas aos alunos. Ele estrutura, enfim, a difusão de resultados de pesquisa pelo meio das revistas científicas especializadas. 
O funcionamento do sistema como um todo se apoia em um princípio central: a avaliação por pares. São os membros de uma mesma comunidade científica, os quais compartilham competências e um vocabulário similar a propósito de um campo comum de questionamentos, que são capazes de julgar a pertinência de um projeto de ensino ou pesquisa, apreciar o valor científico de uma pessoa ou a qualidade de uma publicação. Esse método teve um lugar de destaque na definição e na defesa da identidade de uma disciplina, na limitação de suas fronteiras, na preservação de sua integridade conceitual e metodológica (Klein, 1996, p. 58-59; Holbrook, 2010, p. 321-332).

O estatuto das disciplinas, como conhecemos atualmente, é fruto desse lento processo de construção iniciado na Europa há pouco mais de dois séculos e que se propagou progressivamente, a partir do mesmo modelo, mas com diferenças de temporalidade, ritmo e nuances, em todo planeta. No plano institucional, no campo de ação do mundo acadêmico - formação inicial, média e superior, pesquisa universitária - o recorte disciplinar se impõe doravante como um dado que cada ator, seja ele estudante, professor ou pesquisador, deve levar em conta tanto no exercício de seus projetos intelectuais como na conduta de seu curso de formação ou em sua carreira profissional. Todo projeto com o propósito de estabelecer uma forma de transversalidade entre as disciplinas, colocando, portanto, em questão, mesmo com prudência, uma geografia territorial solidamente estabelecida, terá não apenas que resolver questões científicas, mas também, e talvez principalmente, deverá ultrapassar obstáculos que suas iniciativas geram, no plano simbólico, em termos de poder ou embates econômicos, ou ainda no plano institucional. As lentidões observadas na concretização do pensamento interdisciplinar, cuja precocidade foi lembrada anteriormente, são em parte decorrentes da subestimação do desafio que essa ideia coloca em diversos domínios, e não apenas do ponto de vista científico.

O processo histórico de laicização que acabamos de resumir atribuía ao conhecimento científico um valor intrínseco. Tal valor era instituído como a expressão mais elevada do que se constitui a identidade e a dignidade do ser humano: seu espírito, sua inteligência. No percurso desse movimento, o olhar científico, difratado em disciplinas distintas e autônomas, institucionalizou-se no âmago das estruturas - estabelecimentos de ensino e de pesquisa - criadas em nome da produção, do ensino e da difusão desse conhecimento. Essa não foi, porém, a única finalidade que a ciência assumiu após sua emancipação da religião. Ao lado da imagem do cientista, surgia a do engenheiro e de outras profissões de caráter mais técnico.

Na cidade da Antiguidade, o técnico, seja qual fosse sua competência, devia se contentar com um lugar modesto ao lado do sábio e do filósofo. Isso porque, enquanto esses últimos evoluíam no mundo das ideias e das causas primeiras, da harmonia e da imutabilidade do transcendente, o primeiro se batia com as contradições, contingências e contradições do mundo material (Vérin, 1998). A Idade Média, em que o tangível e o visível não passavam de reflexos de uma realidade mais essencial, da luz de Deus e da cidade divina, não foi capaz de reabilitar o técnico a despeito de numerosas invenções decisivas criadas nesse período da história europeia (Parain, 1979).

É, mais uma vez, no Renascimento que aquele que lida com a materialidade do mundo começa a se libertar de sua posição subalterna. Essa evolução 
toca tanto o artista como aquele que chamaríamos atualmente de engenheiro. Não era, aliás, fácil de estabelecer essa distinção na época: mesmo sem aludir à imagem emblemática de Leonardo da Vinci, podemos destacar que Giotto, Brunelleschi e Michelangelo eram tanto arquitetos e inventores quanto artistas, pintores e escultores. Não apenas essas funções, que hoje em dia tendemos a distinguir e a opor, reuniam-se frequentemente na mesma pessoa, mas os avanços obtidos por esses indivíduos que se dedicaram à resolução de problemas práticos acarretaram progressos decisivos em áreas da ciência mais abstratas e especulativas. É assim que os trabalhos sobre a perspectiva empreendidos por Brunelleschi, Piero della Francesca ou Paolo Ucello permitiram lançar as bases do que se tornou a geometria descritiva (Damisch, 1993) e são inseparáveis das revoluções conceituais que abalaram o pensamento europeu entre o século XV e XVI (Panofsky, 1975).

\section{Como resume Hélène Vérin:}

\begin{abstract}
"Os engenheiros do século XVI ajudaram a abrir caminho para uma filosofia, uma ciência que não temia ser desvalorizada ao se declarar "mecanista" e que se colocou como tarefa descobrir as "leis da natureza". No século XVIII, a "Science des ingénieurs" de B.F. Bélidor (1734), reeditada até o começo do século XIX, sanciona a legitimidade científica das práticas do engenheiro" (Vérin, 1998, p. 17).
\end{abstract}

O mesmo movimento de laicização do conhecimento que criou, aos poucos, a Universidade moderna, cuja finalidade primeira era a progressão e a difusão do saber enquanto valor intrínseco, também exerceu um papel decisivo na legitimação de uma ciência que não era mais desacreditada por ser voltada para a resolução de problemas práti- cos. Na França, antes mesmo que começassem a ser desmanteladas as universidades herdadas da Idade Média, essa legitimação foi confirmada pela criação das primeiras instituições elitistas de ensino características desse país: as "Grandes Écoles". A École des Ponts et Chausseés, fundada em 1747; a École des Mines, em 1783; a École Polytechnique, em 1794; a École des Eaux et Forêts, em 1824. Esses estabelecimentos visavam de antemão à excelência. Devido a uma seleção de estudantes que retinha apenas os melhores; a um ensino de mais alto nível, que se esforçava para levar em consideração os avanços mais recentes da ciência, aos poucos, esses estabelecimentos passaram a ter um lugar mais proeminente na produção do saber tanto em seus próprios laboratórios quanto naqueles criados, graças à iniciativa das pessoas ali formadas, no espaço em que exerciam sua atividade profissional.

Essa distinção entre Universidade e grandes instituições profissionais de formação dos engenheiros é tipicamente francesa. Nos Estados Unidos, por exemplo, a separação não é tão nítida, pelo menos em termos institucionais, inclusive porque, ao observamos a genealogia de muitas universidades norte-americanas, notamos que várias delas surgiram a partir de escolas de agricultura criadas no contexto do Land Grant (Morril Act), em 1862 (Weingart, 2010). Entretanto, uma instituição como o Massachusetts Institute of Technology representa a quintessência de um estabelecimento de ensino e de pesquisa cuja finalidade é associar, no mais alto nível de excelência, ciência teórica e ciência aplicada.

Apoiando-se na formação de engenheiros de alto nível, a ciência de ponta alça voo fora do domínio universitário. A função dos laboratórios criados nas universidades, especialmente nas últi- 
mas décadas do século XIX, é antes de mais nada pedagógica. São lugares "onde se aprende fazendo e fazendo os estudantes fazerem" (Pestre, 2008, p. 41). Paralelamente, nas décadas que antecedem a Primeira Guerra Mundial, a pesquisa se desenvolve como uma atividade essencial nas indústrias, especialmente nos setores que então em pleno desenvolvimento, como a telegrafia submarina, a utilização e produção de energia elétrica, a rádio e a química orgânica. As grandes indústrias, apoiando-se em um grupo de cientistas de excelência, dos quais muitos tinham formação em engenharia, empreendem pesquisas que, apesar de terem como objetivo final aplicações, tocam em problemáticas científicas fundamentais. A universidade, enquanto instituição incumbida de promover o valor intrínseco da ciência, está longe, portanto, de ter tido monopólio no processo de construção da ciência moderna. Ela mesma, aliás, ao longo do século XX, será de mais em mais levada a se distanciar de um ideal de progresso desinteressado do conhecimento para responder às solicitações e às exigências da sociedade, seguindo orientações impostas, cada vez com maior pressão, pelos poderes públicos e estabelecendo parcerias entre os atores econômicos privados e a sociedade civil.

Essa realidade desencadeia vários debates sobre o estatuto da ciência na sociedade. Ao se libertar da tutela da religião - etapa determinante no voo que ela alçou no curso dos dois últimos séculos -, será que se enredou em outros laços que lhe fariam perder sua independência e limitar sua criatividade? Sobre essa polêmica, não me debruçarei aqui. Limitar-me-ei a registrar o fato de que existe uma intensa atividade científica exterior ao mundo acadêmico, ou que ultrapassa os limites de seu papel pedagógico fundamental; ao me perguntar o que isso implicará o ponto de vista do recorte das disciplinas, em suas identidades, nas relações que elas estabelecem entre si e em sua projeção no campo social. A constatação que podemos fazer a esse respeito é que, na pesquisa industrial, as relações entre especialidades científicas não são marcadas pela mesma rigidez que no sistema institucional universitário. Os desafios propostos pela resolução de problemas concretos em setores inovadores mobilizam competências científicas e savoir-faire em torno de objetivos comuns de reflexão e criação.

\begin{abstract}
"O programa de pesquisa da Bell sobre os materiais nos anos [19]30 é um exemplo ideal: por apostar em novos tipos de objetos (o transistor será o produto mais conhecido), foram reunidos em espaços comuns químicos, físicos especialistas em metais, em magnetismo ou eletrônica, especialistas em mecânica quântica [...], cristalógrafos - além de engenheiros de todos os tipos. Cada um tinha uma grande margem de manobra nos programas que ele acompanhava, mas se esperava que participasse de trocas formais organizadas: por exemplo, os especialistas das patentes na companhia ${ }^{4}$ circulavam entre os grupos para decidir os encontros que deveriam ser articulados" (Pestre, 2008, p. 42).
\end{abstract}

Esse movimento se amplia na Segunda Guerra Mundial e durante a Guerra Fria, com enfoques militares ou industriais. A RAND Corporation, um organismo com algumas centenas de pesquisadores, criada inicialmente pela aeronáutica norte-americana e que reunia matemáticos, lógicos, físicos, engenheiros, economistas, administradores e cientistas sociais, é um exemplo típico dessa evolução. Foi lá

\footnotetext{
${ }^{4}$ Pessoas incumbidas de fazer com que os achados científicos dos pesquisadores gerassem patentes que garantissem os lucros da companhia.
} 
que trabalharam com a teoria dos jogos e com a análise de sistema, entre outros. Em torno de objetivos técnicos e operacionais inspirados por preocupações militares, estratégicas ou industriais, desponta uma nova forma de praticar a ciência, baseada em articulações de conhecimentos e competências. É assim que nascerá, por exemplo, uma nova técnica como a dos lasers (Pestre, 2008).

O contexto sócio-político da Guerra Fria e a competição científica e técnica por ele gerada tiveram um lugar determinante no desenvolvimento de um modo de produção do saber no qual a diversidade das disciplinas constituía um recurso e em que, ao contrário do sistema acadêmico, a multiplicidade dos saberes e competências não se projetava em instituições distintas e potencialmente rivais ${ }^{5}$. De modo mais amplo, ao longo do século XX até hoje, essa forma de praticar a ciência se tornou característica de todos os grandes projetos industriais ou de engenharia civil. Construir um novo avião, lançar um satélite, criar um novo remédio, perfurar um túnel submarino exigem a colaboração não apenas de técnicos competentes, mas também de cientistas de alto nível que representam uma grande gama de especialidades, a fim de fazer funcionarem inovações que permitirão resolver os problemas encontrados.

O contraste entre esses dois tipos de organização é real. A Academia tem como missão principal fazer com que saberes de valores intrínsecos progridam e sejam transmitidos. Ela se organiza, pois, em função das facetas desse saber: as disciplinas. As instituições públicas ou empresas privadas encarregadas da resolução de problemas concretos também produzem um novo saber, mas são guia- das pela utilidade que ele pode assumir diante dos objetivos almejados. Portanto, elas se estruturam e funcionam de acordo com essa finalidade. Um relatório da Organização de Cooperação e de Desenvolvimento Econômico (OCDE) ressaltava essa oposição de forma polêmica, intitulando um de seus capítulos "As comunidades têm problemas, as universidades têm departamentos" (1982, p. 127, apud Klein, 1996). O termo "comunidade" aqui faz referência à sociedade em seus diversos componentes, confrontada com a "vida real", ao contrário da instituição acadêmica supostamente movida por visadas abstratas e especulativas.

Há muito tempo, porém, esse contraste não é mais tão marcado na prática. Ao longo do século $\mathrm{XX}$, os pesquisadores e os laboratórios universitários passaram a estabelecer vínculos de mais em mais estreitos com empresas privadas, com as quais essas trocas se multiplicaram. São inúmeras, por exemplo, as descobertas farmacológicas decorrentes de trabalhos empreendidos por universitários. Como não citar a descoberta emblemática da penicilina por Alexander Flemming, em 1928, publicada primeiramente em revistas científicas e que faria surgir uma substância explorada industrialmente destinada a revolucionar a luta contra as doenças infecciosas? Desde então, em todos os países, as relações entre a indústria e a pesquisa universitária não pararam de se reforçar e de se contratualizar. Paralelamente, o financiamento da pesquisa pública tomou a forma de grandes projetos e de licitações cujo conteúdo obedece a prioridades definidas em função de objetivos econômicos, urbanísticos, estratégicos, sanitários, ambientais fixados pelo poder público

\footnotetext{
${ }^{5}$ Isso não quer dizer que essas organizações de finalidade tecnocientífica sejam isentas de recortes institucionais e de barreiras, suscetíveis de produzir concorrências e bloqueios. Essa diferenciação existe, como nota Klein (1996, p.13), mas ela se dá sobre uma base operacional, em função dos tipos de problemas a serem resolvidos ou das funções a preencher, não a priori em função de disciplinas.
} 
em resposta mais ou menos direta de preocupações da sociedade civil. No decorrer dessa evolução, que se acelerou nos últimos cinquenta anos, a produção de conhecimento nas universidades, bem como os conteúdos dos currículos de formação passaram a interagir de mais em mais com a "vida real", com a sociedade, em instâncias públicas e civis, em resposta a solicitações ou mandados decorrentes tanto de instituições públicas quanto de empresas ou, mais recentemente, do meio associativo ${ }^{6}$, e acompanhados dos financiamentos necessários para sua execução.

Duas conclusões advêm dessas constatações. Por um lado, que as disciplinas científicas não são irremediavelmente fechadas a relações entre si; em algumas condições, podem perfeitamente colaborar em nome de uma tarefa comum. Por outro, que a universidade não é exclusivamente consagrada à ciência especulativa: boa parte das pesquisas empreendidas e dos docentes estabelecem vínculos com problemáticas "exógenas" e respondem a demandas de ordem social, profissional, econômica, industrial. Cada vez mais, equipes de pesquisa e departamentos de ensino trabalham com temáticas transversais comuns a várias disciplinas, como o gênero, o urbanismo, o meio-ambiente e a saúde. Nesse caso, o quadro institucional em que foram cristalizadas as especialidades científicas no decorrer da construção da instituição universitária perde sua pertinência; os territórios de identidade e de poder constituídos em seu nome veem suas fronteiras se desfazerem.

Porém, a permeabilidade às preocupações e demandas de diferentes atores da sociedade - públicos, privados e industriais - não é o único fator que colocou em questão o recorte das disciplinas. O pensamento científico não conhece barreiras. É fundado sobre a dúvida, sobre o questionamento das certezas adquiridas. Sob esse prisma, a divisão do real em facetas, examinadas separadamente com ajuda de um aparato teórico e metodológico científico específico, representa antes de mais nada uma comodidade intelectual. Seguindo o percurso da reflexão e do aprofundamento do conhecimento, as divisões instauradas pela separação em disciplinas podem se tornar mais uma fonte de incômodos do que a condição de uma abordagem rigorosa no exercício do pensamento. Nas Ciências Humanas, a divisão entre diferentes ramos como sociologia, antropologia, história, geografia humana, economia e humanidades é com frequência transposta por pensadores que, entretanto, são identificados formalmente em função de um rótulo disciplinar particular. Polanyi é tanto economista quanto historiador e seus trabalhos são abundantemente utilizados por antropólogos (Godelier, 1968). Bourdieu, ícone da sociologia, escreveu um notável posfácio ao texto do historiador de arte Panofsky para mostrar a pertinência sociológica do método aplicado por esse último (Bourdieu, 1967). Os trabalhos de Amartya Sem, prêmio Nobel de Economia em 1998, são de grande valia para todos os pesquisadores em ciências humanas que trabalham com a questão da pobreza e do desenvolvimento. A obra de Levi Strauss alimenta tanto a reflexão filosófica quanto o pensamento antropológico. Poderíamos multiplicar exemplos desse tipo, os quais comprovam que, do ponto de vista do pensamento, o recorte do estudo das sociedades humanas em especialidades distintas

\footnotetext{
${ }^{6}$ É assim, por exemplo, que na França uma parte considerável do financiamento das pesquisas empreendidas sobre a Aids ou as miopatias por universidades ou pesquisadores de grandes instituições de pesquisa, como o CNRS ou o INSERM, é feito por grandes associações como AIDES ou a Associação Francesa contra as miopatias.
} 
não passa de uma ficção metodológica, útil para a exploração metódica dos fatos, mas que o espírito ultrapassa espontaneamente assim que ele ganha certa altura. Entretanto, a coerência interna de algumas dessas Ciências Humanas é fraca. Muitas são divididas no interior por oposições dogmáticas ou pela diversidade dos objetos de estudo, de forma que alguns pesquisadores e professores institucionalmente pertencentes à mesma especialidade científica quase não estabelecem trocas entre si, enquanto entretêm relações regulares com colegas que, apesar de pertencerem a outras disciplinas, compartilham suas ideias ou seus mesmos questionamentos. Um antropólogo, um geógrafo e um economista da saúde não terão grandes dificuldades de se comunicarem entre si, mas frequentemente desconhecem os trabalhos de colegas de disciplina cujas temáticas diferem das suas. Algumas disciplinas, no entanto, têm uma estrutura multipolar e se dividem em identidades opostas: é o caso da geografia, que é desmembrada em geografia física, geomorfologia e geografia humana. Segundo as tradições próprias de cada sistema universitário nacional, a polarização da disciplina pode ser mais ou menos marcada por uma especialização ou outra.

Se as fronteiras nas ciências humanas são porosas, as pontes, as convergências e as hibridizações são talvez ainda mais frequentes nas ciências exatas. Por exemplo, como lembra J. Klein, retomando considerações feitas desde 1986 pelo National Research Council, nos EUA, as interfaces entre a física e a química são tão numerosas que a fronteira entre ambas tende a se esfumaçar ${ }^{7}$. Como esse mesmo autor mostra de modo convincente, atrás da aparente evidência da separação em disciplinas que se impõe no âmago da estrutura universitária como um dado, a realidade é muito mais flexível. A permeabilidade das fronteiras seria mesmo, segundo ele, inerente à própria noção de disciplina: "Permeation is a part of their character" (Klein, 1996, p. 38).

Confrontando-se à inércia e às reações de proteção identitárias que amiúde caracterizam as disciplinas quando são institucionalizadas dentro de uma estrutura voltada ao ensino e à pesquisa, $o$ movimento do pensamento científico, estimulado tanto por sua própria dinâmica interna quanto pelas questões que lhe vêm "de fora", resulta em um potente efeito de transgressão e deslocamento de fronteiras. Esse se traduz por uma recomposição frequente da divisão das disciplinas, marcada por fenômenos de fragmentação e especialização, mas também por reagrupamentos e hibridizações que se dão em torno de áreas de estudo situadas na interface de disciplinas existentes: "In order to study new subjets that do not fit into the domains of established subjects, or even take on the classical characteristics of a discipline, new scholarly domains have been created [...] and boundaries redrawn..." (Klein, 1996, p. 42).

Eis um movimento complexo e, às vezes, contraditório, que está em processo. De um lado, uma fragmentação e uma especialização crescentes ${ }^{8} \mathrm{e}$, de outro, reagrupamentos que geram novas disciplinas híbridas como a astrofísica, a biologia molecular, as nanotecnologias, as ciências cognitivas, os estudos urbanos e a saúde pública. As duas tendências

\footnotetext{
${ }^{7}$ Mesmo se estamos, sem dúvida, bastante longe de uma total convergência, como analisam Vink \& Robles Belmont (2012).

${ }^{8}$ Como exemplo, o Conselho Nacional das Universidades, na França, que avalia e cria as carreiras dos professores universitários, divide as disciplinas médicas em 51 subseções autônomas, em função das patologias e dos órgãos tratados, dos meios terapêuticos utilizados, dos tipos de abordagem (clínica, epidemiologia, saúde pública etc.).
} 
ocorrem simultaneamente - a fragmentação, sendo ela mesma resultado de dissidências que tornam possível novas combinações de competências de disciplinas distintas, mas que se aproximam por interesses científicos comuns. O panorama das disciplinas, do modo que são "rotuladas" no mundo acadêmico, está longe de se constituir como uma realidade congelada. Ao contrário, ele passa por uma constante recomposição sob efeito de múltiplos fatores: o surgimento de novos espaços a explorar decorrentes dos progressos do conhecimento e da evolução do aparato de pesquisa; um desenvolvimento econômico e tecnológico movido por um turbilhão sempre acelerado da busca por inovações; uma socialização crescente da ciência, que é de mais em mais diretamente exposta às questões propostas pela sociedade, em suas instâncias públicas e civis.

Essa dinâmica, entretanto, é acompanhada por um paradoxo maior. Os novos campos de pesquisa e de formação, e as novas comunidades de pesquisadores que se formaram em torno deles, estabilizam-se sob a forma de disciplinas reconhecidas que contribuem para uma recomposição geográfica do saber. No entanto, ao mesmo tempo, essas iniciativas inovadoras também se tornam reféns da lógica dominante das instituições acadêmicas, pois são incitadas a afirmar sua identidade em um contexto marcado pela concorrência em busca da notoriedade e do acesso a recursos. Engajam-se, pois, por sua vez, em uma estratégia de defesa dos territórios em que elas acabaram de ser reconhecidas.

"Yet even as the cultures of physicists and chemists are merging at major synchrotron facilities, even as the boundaries between chemistry, physics, and to some extent biology have blurred in macromolecular research, academic reward systems continue to favor institutionalized categories" (Klein, 1996, p. 6-7).

No final das contas, a história das disciplinas é perpassada por esse confronto dialético entre mudança e reprodução. Ao assumirmos uma perspectiva histórica, as fronteiras entre os campos científicos parecem porosas e escorregadias. Longe de serem cristalizadas e fechadas sobre elas mesmas, as disciplinas estão em constante recomposição. Não cessam de compartilhar objetos de estudo, noções, métodos. Temáticas transversais, como a pobreza, a saúde, o meio ambiente e o gênero criam pontes entre elas. Conceitos caminham entre as especialidades próximas ou distantes (Stengers, 1987; Christin, 2010), muitas vezes ao preço de audácias intelectuais que provocam controvérsias (Bouveresse, 1999; Sokal \& Bricmont, 1997). Porém, a despeito dessa dinâmica de médio em longo prazo, aqueles que, em determinado momento, querem inovar em relação à ordem institucional estabelecida, devem frequentemente lutar para vencer resistências suscitadas tanto pela ameaça que sua iniciativa representa para os poderes e as hierarquias vigentes quanto pela perspectiva dos rearranjos de estruturas e procedimentos que as mudanças preconizadas por eles desencadearão. É, certamente, nas instituições acadêmicas que essa contradição se manifesta com mais força. Isso porque é nelas que a noção de disciplina em seu sentido etimológico ${ }^{9} \mathrm{e}$ histórico conserva todo seu sentido, permanecendo

\footnotetext{
${ }^{9}$ Ou seja, uma comunidade reunida pelo compartilhamento e aprendizagem de um patrimônio singular de conhecimentos. Como lembra Repko (2008, p. 32), o próprio termo "universidade" designava inicialmente uma corporação, uma comunidade que compartilhava as mesmas atividades ou as mesmas características. Em seguida, passou a designar estudantes que seguem uma mesmo tipo de ensino.
} 
a referência primeira sobre a qual se baseia sua organização e seu funcionamento.

Onde situar a questão da interdisciplinaridade em relação ao movimento histórico ao mesmo tempo intenso e contraditório que acabamos de resumir? Podemos, como parece fazer Klein (1996), ver nessas trocas, recomposições, fragmentações e hibridizações variadas manifestações de uma dinâmica interdisciplinar que não se explicita como tal (concealed interdisciplinarity)? Ou devemos ver nessa interpretação uma extensão abusiva da noção de interdisciplinaridade, uma fonte de equívocos que faça perder de vista aquilo que a ideia de interdisciplinaridade possa ter de original e de específico? Por querer ampliar o conceito, será que não corremos o risco de perder seu rigor e não mais dispor de um aparato conceitual pertinente para elaborar uma estratégia capaz de lhe atribuir a forma de uma realidade institucional concreta e perene? Se as disciplinas já se subordinam a uma dinâmica de mudança permanente, ainda que submetida a uma tensão constante entre forças de conservação e renovação, o que traz de novo o projeto interdisciplinar? Se integramos à sua definição esses deslocamentos, essas hibridizações inerentes à própria trajetória das disciplinas e àquilo que constitui a história de sua construção, será que não vamos criar uma confusão que pode entravar e bloquear essas forças de renovação que se exercem naturalmente? Com muita frequência, a reação que suscita o projeto interdisciplinar entre professores e pesquisadores que permanecem fortemente ligados às sua identidade disciplinar é uma denúncia de sua inutilidade. Trocar pontos de vista diferentes, enriquecer-se com as ideias que circulam, introduzir em sua reflexão elementos vindos de fora e colaborar pontualmente com outros olhares em torno de uma temática comum faz parte de toda prática criativa da ciência (Hacking, 2010). Qual é a serventia de criar uma categoria particular para designar essa forma livre de conduzir seu pensamento? Para que serve aprisioná-lo em uma categoria institucional que corre mais o risco de reprimi-lo do que de estimulá-lo?

\begin{abstract}
"Nunca pensei nesses termos e nunca ouvi qualquer colega meu utilizar a palavra "interdisciplinaridade". É claro que essa palavra estava lá, no nome da instituição que nos acolhia, mas como a chamávamos apenas $\mathrm{ZIF}^{10}$, nós nunca a ouvíamos. Nós nos considerávamos indivíduos oriundos de disciplinas diferentes com certos interesses comuns" (Hacking, 2010, p. 81).
\end{abstract}

Às dúvidas que o pensamento interdisciplinar pode suscitar no seio do mundo acadêmico se acrescenta o fato de que, nas pesquisas científicas com perspectiva aplicada - como a inovação tecnológica, a cirurgia de ponta ou o urbanismo, por exemplo - a colaboração entre especialidades tecnocientíficas é natural, dispensando a necessidade de criar uma categoria metodológica ou teorizar a esse respeito. Assim, somos levados a nos perguntar se a dificuldade que o pensamento interdisciplinar há tanto tempo enfrenta para se impor não se deve, em parte, ao fato de não se distinguir suficientemente de um modo de produção de conhecimento baseado em disciplinas que, ao mesmo tempo, provaram seu rigor e eficiência e também sua flexibilidade face aos desafios instaurados pelo progresso do conhecimento e pela crescente socialização da ciência. É essa discussão que será objeto de minha reflexão a partir de então.

${ }^{10}$ Zentrum für Interdisciplinäre Forschung - Centro de Pesquisa Interdisciplinar (Bielefeld, Allemagne). 
Não tenho a pretensão de esgotá-la, mas sim de tentar colocar algumas linhas de pensamento que podem ajudar a avançar nesse terreno.

\section{As múltiplas facetas do pensamento interdisciplinar}

O pensamento interdisciplinar que, durante grande parte do século XX, caminhou paralelamente a um movimento de intensa especialização da ciência e da técnica, ramificou-se em percursos diferentes, inspirados por motivações díspares. Gerou projetos que, mesmo quando reivindicam essa mesma perspectiva interdisciplinar, têm frequentemente pouca coisa em comum. Essa diversidade não é em si criticável, mas, como disse na introdução, é preciso que ela seja explicitada e assumida. Caso contrário, instaura-se uma confusão de ideias que impede identificar claramente a contribuição da abordagem interdisciplinar na prática científica e que prejudica a elaboração de estratégias capazes de lhe dar um lugar em um universo institucional amplamente dominado pela separação em disciplinas.

Certamente, se analisarmos minuciosamente, as nuances entre as iniciativas que se dizem interdisciplinares são inúmeras. $\mathrm{O}$ que as separa nem sempre é salientado de forma clara, até porque com frequência elas mesmas mantêm certa confusão quanto a seus fundamentos teóricos e seus objetivos. Para começar a colocar um pouco de ordem nesse emaranhado, acredito que é possível tentar agrupá-las em três grandes categorias, sendo que cada uma almeja estabelecer relações entre as disciplinas a partir de um ângulo de visão diferente, em busca de objetivos distintos.

\section{Em busca da unidade perdida}

Como acabamos de ver, o que define talvez de forma mais geral o pensamento científico moderno, como ele gradativamente se construiu no cerne do mundo cultural europeu no prolongamento da revolução paradigmática do Renascimento, é o abandono de uma hierarquia entre as vias pelas quais o espírito humano apreende o mundo; o fim da busca por uma convergência de olhares e de questionamentos voltados para a identificação de causas e princípios primeiros. Cada nível de observação do real, cada ângulo a partir do qual ele é explorado, cada perspectiva metodológica, cada corpus de conhecimento passa a ser reconhecido com uma pertinência e uma legitimidade própria. Se aproximações e conexões aparecem entre vários achados, sua utilidade se impõe a partir da observação dos fatos, e não a partir de um esquema de articulação estabelecido a priori.

Desde o século XIX, vozes se levantavam para condenar essa fragmentação do saber. É o que ocorreu na Alemanha com August Boeckh e Du Bois- Reymond (citados por Weingart, 2010). Na França, Auguste Comte, na perspectiva de sua "filosofia positiva", também aspirava reunir as ciências em um tronco comum:

\footnotetext{
"Torna-se possível e mesmo necessário esquematizar diversos conhecimentos adquiridos, que atingiram um estado fixo e homogêneo, para coordená-los a fim de os apresentar como vários ramos de um único tronco, ao invés de continuar a concebê-los apenas como vários corpos isolados" (citado por Kremer-Marietti, 2003).
} 
Essa aspiração à unidade do conhecimento não parou de acompanhar, em paralelo, o movimento de fragmentação e de recomposição que caracteriza, desde o início, a evolução da ciência e das técnicas. Ela está na raiz de uma corrente de pensamento que assumiu um lugar de bastante destaque, ao longo do século XX, na filosofia das ciências e na pedagogia, sob a influência, entre outros, de Otto Neurath e de Rudolph Carnap que, em 1938, organizaram a publicação de uma Enciclopédia da Ciência Unificada (Neurath et al., 1938).

$\mathrm{O}$ apelo de um retorno à coerência perdida do saber está no âmago de tal abordagem pedagógica. Seu propósito é restituir o espírito de uma formação humanista que forneça aos indivíduos conhecimentos e ferramentas intelectuais de que eles precisam para se comportarem como cidadãos responsáveis. Era esse o fio condutor do General Education Movement, que surgiu nos Estados Unidos no entre-guerras. Após o segundo conflito mundial, no contexto da Guerra Fria, esse enfoque pedagógico se tornou uma arma que alguns queriam colocar a serviço da defesa da democracia e da resistência ao totalitarismo. Essa visada é explicitada no título de um relatório publicado em 1945: "General Education in a free society" (Harvard Education Committee, 1945, citado por Repko, 2008, p. 5).

Essa abordagem de ensino estabelecia vínculos com o pensamento interdisciplinar, sem necessariamente reivindicar essa relação. Ao menos o prefigurava na medida em que pregava uma ultrapassagem das especializações e uma abertura do ensino acima das barreiras que separam as disciplinas. Nos anos 1960 e 1970, com o profundo questionamento dos moldes de organização e de pensamento que constituíam a base imaterial das sociedades filiadas à herança cultural europeia, essa exigência de abertura se afastou das perspectivas geopolíticas que podiam tê-la inspirado por um momento para se tornar, em vários países, uma reivindicação poderosa da juventude. Não eram apenas as barreiras impostas por regras sociais e morais rígidas que era necessário derrubar, mas também as que enclausuravam o pensamento em categorias dissociadas umas das outras. Na França, a reforma radical do ensino superior ocorrida imediatamente após as manifestações dos estudantes de maio de 1968 (lei Faure para a reforma das universidades) foi amplamente inspirada no objetivo de aproximar disciplinas que, no antigo sistema das faculdades (de letras, de ciências, de direito, de economia e de medicina), permaneciam estrangeiras em relação às demais. Assim, foram criadas as Universidades multidisciplinares, reunindo em uma mesma estrutura administrativa especialidades científicas que, até então, não tinham tido oportunidade de se encontrarem e, muito mesmo, de colaborarem entre si: aqui, a medicina e a sociologia; acolá, a economia e a física etc. Não comentaremos o sucesso modesto que essas aproximações administrativas tiveram em termos de colaborações efetivas. Mais significativo para nós é o fato de a ideia já estar presente. Ampliar as formações e lutar contra uma especialização excessiva que não prepara bem o estudante para lidar com uma multiplicidade de questões às quais ele deverá responder em sua vida profissional e de cidadão se tornaram objetivos da universidade. A realização desse projeto intelectual nem sempre esteve à altura das ambições anunciadas, mas a ideia ganhou legitimidade por ter inspirado o próprio projeto institucional.

Essa abordagem está longe de ser exclusividade da França. Ao contrário, ela passa a inspirar numerosas universidades no mundo. É o caso, por 
exemplo, nos Estados Unidos, do programa General Education, assim definido atualmente pela Universidade de Harvard:

\begin{abstract}
"Harvard has long required that students take a set of courses outside their concentration in order to insure that undergraduate education encompasses a broad range of topics and approaches. The new Program in General Education seeks to connect in an explicit way what students learn in Harvard classrooms to life outside the ivied walls and beyond the college years. [...] These courses aim not to draw students into a discipline, but to bring the disciplines into students' lives." 11
\end{abstract}

Nas últimas décadas do século XX, assistimos a um profundo abalo nos aparatos conceituais a partir dos quais as sociedades humanas refletem sobre si e analisam o mundo em que existem. Um movimento de globalização econômica e social de uma dimensão sem precedentes estabelece entre elas estreitas interdependências em escala mundial. Os avanços da ciência exigem a reconsideração profunda da condição humana e de suas relações com a matéria. O surgimento da questão ambiental como tema maior para o futuro da humanidade obriga a revisar a clivagem homem/natureza sobre a qual se construiu a civilização moderna europeia e o pensamento científico que nela achou suas primeiras raízes (Raynaut, 2015b). É uma realidade complexa e híbrida que precisamos procurar compreender a fim de agir sobre ela da melhor forma possível. Uma realidade que é fruto da imbricação de fatores de natureza diversa: culturais, sócio-políticos, econômicos, técnicos e biofísicos. Hibridização e complexidade se tornam palavras-chave que se impõem daqui em diante, mais do que nunca, para descrever o desafio com o qual nos confrontamos na tentativa de conhecer e compreender o mundo.

Formações altamente especializadas, apesar de apresentarem inigualável profundidade de competências e conhecimentos, não conseguem dar o campo de visão amplo indispensável para apreender a multiplicidade dos determinantes que intervêm na gênese de muitos problemas (ambientais, sanitários, urbanos, econômicos, dentre tantos outros) os quais temos que resolver atualmente; tampouco para identificar o modo como esses fatores interagem a fim de achar soluções.

Esse caráter compósito não diz respeito somente a problemas de ordem pragmática. São novas categorias de pensamento que as reviravoltas conceituais trazidas pelos avanços da ciência e das técnicas tornam necessárias. No campo da biologia e das neurociências, o ser humano perde progressivamente o estatuto de extraterritorialidade que, na cultura europeia, a religião cristã e, depois, o pensamento cartesiano lhe tinham outorgado. Ele passa a se inserir na filiação comum compartilhada por todos os seres vivos do planeta. Seu corpo se torna manipulável como qualquer outra matéria viva ou inerte. Seu cérebro é explorado pela ciência para identificar os mecanismos biofísicos dos quais emana a consciência - mecanismos complexos em sua arquitetura, mas cujos componentes, no final das contas, pertencem a um mesmo fundo biológico, comum a todos os seres vivos. A consciência não pode mais ser invocada como uma faculdade sui generis, cuja posse fundaria o estatuto ontologicamente diferente do ser humano.

\footnotetext{
${ }^{11}$ Fonte: www.generaleducation.fas.harvard.edu (2015).
} 
Se o ser humano se junta assim à natureza, ela sofre, por sua vez, um movimento intenso de antropização. O planeta inteiro, do nível mais local ao mais global, passa a ser profundamente remodelado pela intervenção humana. Ele se torna progressivamente um artefato (as mudanças globais do clima sendo o exemplo mais evidente dessa evolução). Entramos na era da Antropocena. Simultaneamente, as escalas de tempo e espaço se misturam. De modo cada vez mais evidente, o que acontece aqui e agora se impõe como algo que pode ter consequências decisivas sobre o que vai acontecer em outros lugares e um futuro talvez longínquo. As decisões políticas, econômicas e técnicas devem então levar em conta suas possíveis repercussões nas gerações futuras. Devem considerar também as estreitas interdependências culturais, políticas e econômicas tecidas pela globalização, que se coordenam com a aceleração e intensificação da comunicação, de modo que, em um curto intervalo de tempo, um acontecimento local pode repercutir até nos confins mais recônditos do planeta.

As categorias do pensamento antigo que fundavam a cultura ocidental - e, em seu rastro, o pensamento científico - não conseguem mais apreender essa nova realidade. Os limites aparentemente claros e estáveis nos quais se fundava outrora o cenário mental em função do qual a ação individual ou coletiva podia traçar seu caminho, tendem a se dissolver. Humano/não-humano; vida/morte; identidades sexuais; modalidades da filiação biológica - para citar apenas alguns exemplos - não se impõem mais como dados intangíveis, constitutivos das próprias condições nas quais se constrói a existência humana, mas se tornam objeto de debates, sujeitos a reinterpretações, a redefinições em resposta às aspirações individuais e aos propósitos coletivos. É um imenso campo de trabalho que se abre para o pensamento. Não estão em questão aqui meros jogos de ideias, mas questões candentes às quais as sociedades contemporâneas devem responder para poder decidir e agir. É o que evidencia o lugar ocupado pelos debates éticos, na sociedade civil, nas empresas e até nos parlamentos; os quais, como na França, podem desembocar em disposições legais destinadas a enquadrar com princípios jurídicos as respostas dadas a dilemas jamais encontrados na história humana.

Conduzir essa reflexão, empreender essas discussões e colocar esses princípios em prática exigem abertura de espírito, visão ampla, capacidade de lidar com a complexidade. Essa exigência não se limita a uma pequena elite de pensadores e de responsáveis que seriam habilitados a destrinchar esses temas. Nas sociedades contemporâneas que se dizem democráticas, não é mais suficiente que as regras sejam impostas por uma autoridade moral superior para que elas sejam aplicadas. Elas precisam também serem reconhecidas como legítimas pelos indivíduos que terão de aplicá-las. É, portanto, o próprio cidadão que deve acompanhar a necessária reconstrução dos moldes de pensamento e ser capaz de ultrapassar um ponto de vista estritamente pessoal para pensar nas múltiplas implicações de suas escolhas e atos. Em alguns casos, tal capacidade é adquirida por meio de uma reflexão pessoal nutrida pela experiência. Na maioria, porém, ela exige a aprendizagem de ferramentas intelectuais que permitem pensar a complexidade da realidade, a diversidade de ângulos sob os quais é possível apreendê-la. As formações tradicionais - tanto no ensino básico quanto no superior - não foram concebidas nesse espírito - ao menos, não de forma suficiente. É por isso que um dos maiores eixos de reflexão que inspiram a busca pela renovação das abordagens 
pedagógicas põe em destaque a necessidade de adotar um enfoque que ultrapasse a fragmentação em domínios de conhecimento, para estabelecer pontes entre as disciplinas e formar os alunos para operar sínteses do que elas nos dizem da realidade. Essa chamada à interdisciplinaridade é um desafio identificado pela $\mathrm{OCDE}^{12}$ desde 1972 , no ensino superior e na pesquisa (Apostel, 1972). Porém, ele também está em questão no ensino escolar básico (Lenoir \& Sauve, 1998), cujo objetivo é formar, desde a mais tenra idade, cidadãos responsáveis.

A interdisciplinaridade se tornou, portanto, uma temática central da reflexão sobre a renovação das abordagens pedagógicas em todos os níveis de ensino. Nos anos de 1970, como mencionamos anteriormente, a ideia inspirou reformas universitárias na França e em outros países. Repercutiu, de forma particular no projeto, a concepção de diversificar as formações oferecidas em currículos antes altamente especializados: os estudantes de medicina, por exemplo, passando a ter uma formação complementar em sociologia, antropologia ou economia. A partir dos anos de 1990, a novidade foi a multiplicação de formações organizadas especificamente em torno da visada interdisciplinar. Esse movimento foi especialmente ativo nos países cuja estrutura universitária é mais flexível do que na Europa, em que o peso da história cria amiúde uma rigidez ainda muito difícil de superar. É o que ocorreu nos Estados Unidos, em que os diplomas universitários interdisciplinares se multiplicaram nas últimas décadas. O Brasil foi pioneiro nesse movimento, a ponto de o desenvolvimento da abordagem disciplinar se tornar um dos objetivos centrais da instituição de coordenação e avaliação do ensino superior (CAPES). Também, na Ásia, várias universidades evidenciaram sua preocupação em promover a interdisciplinaridade. É o caso, por exemplo, em Singapura, da criação do National Environment Research Institute.

O objetivo dessas formações, geralmente centradas em uma problemática híbrida e complexa como o desenvolvimento urbano, o meio ambiente, a saúde ou o gênero, é permitir que os estudantes tenham uma visão transversal e sintética do tema abordado. O que implica, em primeiro lugar, introduzi-los a conhecimentos científicos em diferentes especialidades disciplinares relativas à temática estudada. Não está em questão formar especialistas em cada área, mas sim tornar os alunos capazes de identificar os fatores diversificados e as dinâmicas múltiplas operando nas situações concretas que analisam; de estabelecer relações entre fenômenos, tendências e amarras referentes a campos distintos da realidade, às vezes muito afastados uns dos outros. A segunda competência essencial que deve ser adquirida é justamente a capacidade intelectual de integrar e sintetizar informações múltiplas e heterogêneas.

Trata-se de um procedimento pedagógico específico, necessariamente inovador por se afastar dos currículos acadêmicos tradicionais, cujo objetivo final é conduzir o estudante, degrau por degrau, a um nível de competência máxima em um domínio de conhecimento específico. Exige também muito rigor, pois o esforço de síntese realizado não deve conduzir à formulação de simples opiniões, mas a conclusões apoiadas em um raciocínio solidamente construído. Allen Repko descreve e propõe de forma muito detalhada uma metodologia de formação que responde a esses objetivos (Repko, 2008). Não a

\footnotetext{
${ }^{12}$ Organização de Cooperação e Desenvolvimento Econômico.
} 
retomarei detidamente aqui. Ressalto apenas que ela ilustra perfeitamente uma abordagem de interdisciplinaridade, cuja finalidade é formar o que chamamos, em outro momento, de "espíritos esclarecidos" (Raynaut \& Zanoni, 2011), que tenham certo recuo em relação aos saberes compartimentados produzidos pelas disciplinas e que sejam, por isso, capazes de se confrontarem aos novos desafios intelectuais aos quais nossas sociedades contemporâneas devem fazer face. A interdisciplinaridade é considerada aqui fundamentalmente como um modo de pensamento que privilegia a pesquisa da transversalidade e que se esforça para valorizar o patrimônio de conhecimento que as disciplinas colocam à sua disposição. Essa forma de pensamento pode se exercer tanto de modo individual quanto de modo coletivo, e pode se dedicar à resolução de problemas concretos, bem como investir em uma reflexão teórica destinada a esclarecer questões conceituais ou éticas à luz dos avanços recentes do conhecimento científico. Há aqui uma concepção legítima de interdisciplinaridade, a qual se insere em uma longa tradição que visa à restauração da unidade do conhecimento, à exploração do pensamento complexo e à formação de cidadãos responsáveis. Sua legitimidade será cada vez mais forte à medida que ela saberá se distinguir de outras abordagens que, embora almejem também ultrapassar as fronteiras disciplinares, fazem-no com outros objetivos, segundo outra perspectiva e outros métodos.

\section{Rumo a uma interdisciplinaridade operacional}

Às vezes escutamos falar, de maneira crítica ou ao menos com certa condescendência, sobre o cará- ter instrumental que a interdisciplinaridade assume quando se aplica à resolução de problemas. "Solving social and technological problems and borrowing tools and methods exemplify instrumentalism", observa Klein (1996, p. 10-11), acrescentando, na sequência: "Instrumentalism, though, minimizes critical reflection. It retards or altogether ignores analysis of ends and means, even when impediments to efficient problem solving are acknowledged".

A noção de instrumentalização é usada aqui de forma excessivamente geral e vaga, pois pode ser aplicada a situações muito diferentes. Com efeito, os problemas que procuramos resolver não são exclusivamente de natureza empírica, podendo também ser de ordem conceitual e filosófica - mesmo quando se espera que a resposta trazida tenha grandes consequências na prática. É o caso, por exemplo, da ética médica, que deve trabalhar à luz dos avanços mais recentes da genética, da bioquímica, da medicina e da cirurgia, mas também levar em conta as evoluções sociais e criar novos conceitos e novos princípios para pensar sobre noções fundamentais como as de vida (em todas suas formas), de reprodução sexual, de morte. Trabalho de crítica e de inovação conceitual que não deixa de se inserir em uma perspectiva predominantemente instrumental, pois tornará possível definir de modo mais concreto as práticas e os procedimentos terapêuticos relacionados a enxertos, à medicina reprodutiva e ao acompanhamento do fim da vida. A dimensão conceitual e a instrumental não se opõem nesse caso, mas são intimamente ligadas e o modo de pensamento transversal que evocamos anteriormente pode também desembocar em uma práxis.

Inversamente, trabalhar de forma interdisciplinar sobre questões de pesquisa aplicada pode levar as disciplinas envolvidas a renovar sua pró- 
pria abordagem teórica. Especialmente, esse foi o caso das pesquisas conduzidas em conjunto pela medicina, pela epidemiologia e pelas ciências sociais a propósito da Aids. Esses trabalhos levaram disciplinas como a antropologia e a sociologia a aprofundar questionamentos relacionados à sexualidade, às relações homem/mulher e ao papel da sociedade civil na formulação das políticas públicas - temáticas que, antes disso, elas haviam apenas levantado (Raynaut, 1997). A necessidade de se confrontar com um problema de saúde pública lhes trouxe avanços teóricos consideráveis. Mais uma vez, visada prática e trabalho teórico podem ser complementares.

Também é fato que certas cooperações entre especialidades científicas e técnicas têm como meta a realização de uma tarefa específica, a obtenção de um resultado identificado previamente. Isso ocorre frequentemente na indústria, na engenharia civil, no planejamento territorial e na medicina, entre muitos outros exemplos. Quando é assim, o objetivo é fixado desde o início. As questões que permanecem abertas são as da forma de atingi-lo, das múltiplas competências que devem ser reunidas para tal e das condições nas quais essa colaboração será organizada. Esse modo de organização de conhecimentos e habilidades em uma prática coletiva foi praticado ao longo dos séculos nas grandes obras arquitetônicas ou nas realizações técnicas que exigem a intervenção conjunta de profissionais de diversas áreas de especialização. Foi desse modo que, no passado, foram construídas as catedrais e também que, recentemente, aconteceu a Revolução Industrial. Hoje em dia, as grandes inovações contemporâneas, seja no espaço, na aeronáutica, na bioquímica ou na área médica, são, em mais alto nível, fruto de uma coordenação de competências científicas e técnicas, mas amiúde também econômicas e sociais. Unir competências diversas era, por exemplo, o objetivo da RAND Corporation, que citamos anteriormente. Não é, aliás, apenas no domínio técnico que essas competências são procuradas. Empreender um projeto destinado a revitalizar um espaço urbano, a combater a pobreza, a violência ou a elaborar uma estratégia de proteção ambiental também exige a reunião de profissionais de múltiplos horizontes disciplinares para fazê-los colaborar em uma perspectiva aplicada.

Estamos aqui diante de uma forma de interdisciplinaridade que não chamaremos de instrumental, para evitar a confusão que esse termo pode trazer, mas sim de operacional. A distribuição de papéis entre os diferentes participantes se organiza em torno de um objetivo comum, de uma meta a se atingir. Tanto esses papéis quanto o modo como eles se articulam são mais ou menos precisados de forma clara com antecedência, dependendo se tratam de em uma fase de ajustes ou, ao contrário, se são seguidos procedimentos já conhecidos graças à experiência adquirida. Em alguns casos, estabelece-se entre as especialidades uma relação de trabalho em que os envolvidos realizam tarefas definidas ou respondem a perguntas precisas em resposta às demandas formuladas por uma disciplina que conduz o processo como um todo. É o que observamos, por exemplo, na área médica, como no caso do tratamento cirúrgico das patologias cardíacas, em que se coordenam, visando ao processo de cura, as competências do radiologista, do imunologista, do anestesista, do farmacêutico e até mesmo do especialista em materiais compósitos ou da engenharia genética. Ainda na área da saúde, em oncologia, por exemplo, a rede de colaboração pode ultrapassar as disciplinas técnicas e médicas 
para integrar competências de ordem psicológica ou social, cujas intervenções concomitantes ao próprio tratamento podem ser determinantes para o sucesso final do percurso terapêutico.

Poderíamos citar muitos exemplos dessa interdisciplinaridade operacional, que também pode ser encontrada no campo do meio ambiente, do planejamento territorial e do urbanismo, entre muitos outros. Sua aplicação se dá frequentemente de forma pragmática, por meio de colaborações que aos poucos se estabeleceram em resposta às questões que surgiam e às dificuldades encontradas. Durante muito tempo, essas práticas não sentiram necessidade de se referirem à noção de interdisciplinaridade, a qual advém de uma esfera abstrata que lhes era estrangeira. Progressivamente, porém, a necessidade de conciliar as formações especializadas com as novas condições para o exercício das profissões se impôs. Dali em diante, além de competências mais consolidadas em um campo científico e técnico específico, os profissionais devem ser capazes de trabalhar em equipe, com parceiros de outras áreas de conhecimento, dotados de competências e habilidades distintas das suas. Isso significa ter a capacidade de compreender sua linguagem e seus métodos e de dialogar com eles para encontrar campos de convergência, conseguindo assim articular suas intervenções. Daí surgiu a necessidade de sistematizar a aquisição dessas capacidades por intermédio de uma pedagogia apropriada. Formar profissionais que possam pôr em prática suas competências num âmbito interdisciplinar tornou-se, então, um objetivo pedagógico nos cursos de ensino profissionalizante. É o que ocorreu nos grandes centros de formação em engenharia, que já tinham há muito uma tradição de diversificação de ensino. Nas "Grandes Écoles" de engenharia francesas, a interdisciplinaridade passou a ser um objetivo explicitado, bem como em instituições norte-americanas prestigiosas, como o Massachusettes Institute of Technology (MIT). A um nível mais amplo, a aplicação do enfoque interdisciplinar nas formações profissionais tem-se tornado hoje uma questão pedagógica amplamente debatida (Lenoir, 2000; Lenoir et al., 2006; Delhaye, 2014). Essa discussão envolve, em primeiro lugar, profissionais como os professores, os profissionais de saúde e os de assistência ou trabalhos sociais. Podemos, porém, encontrar essa preocupação em campos mais técnicos, como as ciências biológicas ou as disciplinas do meio ambiente. Em 2013, o Brasil tinha 174 mestrados profissionais interdisciplinares reconhecidos pela CAPES. A questão da abordagem interdisciplinar na formação dos engenheiros ocupa um lugar central na reflexão pedagógica conduzida pela universidade brasileira (Bevilacqua, 2014; Weber et al., 2014).

Há realmente, nesse caso, busca pela interdisciplinaridade no sentido geral que podemos atribuir à noção, ou seja, trocas e cruzamento entre conhecimentos e competências especializados. Porém, aqui, ao contrário do tipo de abordagem a que aludimos previamente, essa visada não é fundamentalmente conceitual. Sem dúvida, a reflexão teórica também deve se fazer presente, pois toda prática põe em jogo conceitos, mas o objetivo não é criar novos instrumentos de pensamento e sim formar profissionais que possam colaborar melhor na busca de um objetivo operacional comum.

Embora a questão da relatividade dos saberes continue sendo central nesse tipo de formação, como em qualquer outro projeto interdisciplinar, os objetivos pedagógicos, o conteúdo das formações e a natureza das aprendizagens são necessariamente muito diferentes daqueles dos projetos cuja finali- 
dade é contribuir para a emergência de uma nova forma de pensar em um mundo contemporâneo em permanente mudança. No entanto, essa interdisciplinaridade que chamamos de operacional não deve, por conta disso, ser julgada com condescendência, pois remete a questões de fundamental importância para o nosso futuro, visto que o tratamento dos problemas complexos que as sociedades contemporâneas devem encarar exige uma renovação profunda das práticas profissionais, a qual somente poderá ser efetiva se levar em conta uma reflexão crítica sobre princípios e categorias de pensamento que inspiram a ação. Para citar apenas um exemplo, a formação atual dos profissionais de saúde envolve obrigatoriamente questões éticas colocadas atualmente pela evolução radical de práticas e instrumentos terapêuticos. Operacionalidade e trabalho conceitual são, assim, estreitamente complementares.

\section{Inovar na produção de conhecimentos sobre uma realidade híbrida e complexa}

Não se pode negar que seja essencial encontrar meios para tirar partido da diversidade de saberes e habilidades de que dispomos, seja para renovar os instrumentos conceituais pelos quais pensamos o mundo, seja para agir sobre ele de forma mais eficaz e mais sustentável tecnicamente, economicamente ou socialmente. Todavia, o desafio da interdisciplinaridade não se limita à simples formalização, sob novas configurações, daquilo que já conhecemos e sabemos fazer. Ele alcança sua plena dimensão quando nos preocupamos em produzir novos conhecimentos sobre uma dada realidade, já que tomamos de mais em mais consciência de que ela é produto de uma combinação de fatores e dinâmicas heterogêneos, cuja interação lhe dá uma coerência orgânica. Esses sistemas complexos, que englobam campos parciais da realidade sobre os quais cada disciplina lança seu próprio olhar, constituem um novo território científico que deve ser descoberto e explorado. Trata-se aqui de ir além de um percurso intelectual que se limita a aproximar, cruzar e sintetizar a posteriori os conhecimentos já produzidos por diferentes ciências. O alvo é reunir essas ciências em dispositivos de pesquisa combinados que se voltem para temáticas e objetos científicos situados na interface entre os espaços de observação, análise e teorização, almejados até então separadamente.

Essa abordagem não pode mais se confundir com os movimentos espontâneos de aproximação e de troca que, como vimos na primeira parte deste artigo, caracterizam a própria vida das disciplinas. Não é preciso retomar aqui essa flexibilidade e essa dinâmica. No entanto, parece-me necessário afirmar que teríamos mais clareza, nesse debate amiúde confuso sobre a interdisciplinaridade, se distinguíssemos essa porosidade das fronteiras das disciplinas, esses movimentos de "crossing boundaries" ou de "bridge building” - como é chamado por Klein (1996) - de uma abordagem de pesquisa baseada justamente na diversidade de olhares e de métodos científicos para confrontar a heterogeneidade e a complexidade do real, a fim de compreender os problemas que temos de resolver atualmente. Essa afirmação parece levar a um paradoxo: a interdisciplinaridade, assim concebida, não significa o questionamento das identidades disciplinares. Ela implica, ao contrário, um reconhecimento da especificidade dessas identidades - considerando-as não congeladas em uma forma definitiva, mas dinâmicas. Assim, trata-se de entendê-las no modo em que se apresentam em um determinado momento do seu constante movimento de recomposição. A interdisciplinaridade representa 
aqui um esforço determinado e inovador para elaborar uma metodologia que permite articular essa diversidade de aparatos teóricos e metodológicos a serviço de um percurso de pesquisa comum. Pode acontecer que as colaborações desemboquem, no final das contas, em redefinições das fronteiras entre as disciplinas, inserindo-se assim no movimento mais geral de recomposição do cenário científico. Isso somente pode acontecer, porém, ao cabo de uma experiência compartilhada que conduz à conclusão de que essa redefinição se faz pertinente. Não é tal recomposição, de forma alguma, o objetivo a priori do percurso disciplinar que, ao contrário, é fértil graças à diversidade de olhares e de abordagens que almeja articular.

É, sem dúvida, o caráter híbrido das questões que temos de tratar dessa forma que constitui o desafio maior de tal projeto. A tarefa se torna mais árdua quando esse hibridismo exige aproximações entre campos de pesquisa até então estranhos entre si. Com efeito, os avanços recentes da ciência, conciliados com a ampliação crescente do campo de intervenção das técnicas que eles possibilitam, esfumaçam tanto os limites conceituais quanto físicos que se colocavam antigamente entre o ser humano e o resto do mundo. É o hiato entre o homem e a natureza, constitutivo da cultura ocidental e do pensamento científico que a ela se fundiu, que passa assim a ser colocado em questão (Raynaut, 2015a).

É na exploração desse espaço novo, a ser descoberto com a indispensável colaboração entre as ciências humanas e as que tratam da materialidade do mundo, que a exigência de uma conduta interdisciplinar de pesquisa encontra sua mais ambiciosa fonte. É nesse prisma também que essa colaboração pode se revelar mais inovadora e mais fecunda para a resolução dos problemas nos quais se confronta hoje a espécie humana, na medida em que se impõe a evidência de que a teia da nossa história e de nosso destino é traçada, em última instância, não pelas leis que regem a matéria, mas pelos objetivos, sonhos, fantasmas que inspiram nossa ação sobre ela, os usos que fazemos dela.

Não é apenas do movimento de um pensamento especulativo que nascem as dúvidas e as questões que surgem dessa nova realidade híbrida. Elas derivam antes de mais nada dos desafios inéditos trazidos pelas interdependências não elucidadas e muito menos controladas que se desenvolvem entre a capacidade de intervenção sobre a matéria - que as ciências e as técnicas dão mais do que nunca ao ser humano - e o universo imaterial das ideias, objetivos, aspirações, desejos, emoções e fantasias que inspiram o uso que ele faz dessa capacidade. Enquanto, seguindo um esquema de pensamento cartesiano, era possível separar em dois universos distintos a mecânica das coisas, que segue seu curso inflexível, e uma humanidade cuja natureza, em suas dimensões físicas e espirituais, lhe era completamente irredutível, as ciências podiam atuar em um ou outro desses campos sem ter de se cruzar. Hoje, porém, a experiência cotidiana nos coloca diante da evidência de que essa separação não é mais sustentável. O exemplo mais elucidativo diz respeito às possibilidades que a biologia, a genética $\mathrm{e}$ a medicina nos deram de manipular o corpo humano e suas funções orgânicas como qualquer outro tipo de matéria. Essas possibilidades abrem espaços completamente novos às estratégias individuais e coletivas no campo, por exemplo, da procriação, da definição do gênero, dos princípios que guiam a decisão de manter ou não em vida um ser humano em situação de doença extrema. Portas fechadas até então se abrem para a satisfação dos desejos, para a realização de sonhos que, em outras épocas, estavam completamente 
fora da nossa alçada. Na medicina, mais e mais gestos técnicos (enxertos, manipulações genéticas, reprodução assistida etc.) acarretam questionamentos da nossa própria definição de humanidade e do estatuto que lhe atribuímos, tornando necessárias escolhas políticas e sociais. De forma mais ampla, e em múltiplas escalas, nosso conhecimento sobre a estrutura e os mecanismos da matéria tanto viva quanto inerte nos convida a tentar submetê-la à nossa vontade, de moldá-la de acordo com nossos projetos. Assim, não podemos mais pensar sobre o futuro do clima do planeta e suas consequências sobre as condições de nossa vida material sem nos interrogar sobre as aspirações, os desejos e as fantasias que comandam nosso uso dos recursos naturais.

Essa realidade híbrida, nascida do confronto entre nossas aspirações e um mundo objetivo que se submete parcialmente a elas sem perder nada das leis que o regem, desencadeia, por sua vez, incontáveis questões, decorrentes das consequências imprevisíveis de uma apropriação do mundo ainda nunca ocorrida na história da humanidade. Surgem, também, dos desafios culturais e sociais provocados pelo desabamento ou pelo recuo dos limites objetivos até então intangíveis que envolviam as capacidades do homem de intervir sobre ele mesmo e sobre seu entorno. Quais repercussões as possibilidades dadas pelas ciências e pelas técnicas têm sobre as relações entre membros de uma mesma sociedade (em função do sexo, da idade, da posição e do papel que ocupam)? Como analisar e prever as consequências que escolhas técnicas e econômicas feitas aqui e agora podem ter para outros habitantes do planeta e para as gerações futuras? Eis aqui, como dissemos anteriormente, perguntas que mobilizam reflexões éticas e políticas que podemos conduzir tomando como base o estado atual do conhecimento. Contudo, são também interrogações que demandam pesquisa científica. Nossa ignorância é grande a respeito das interações que se estabelecem entre os fenômenos e as dinâmicas de dois campos até então bastante separados da ciência: o que se dedica à matéria considerada sob todas formas e facetas (inclusive aquela, viva, do ser humano) e aquele, incorpóreo, que se volta às ideias, às representações, aos princípios, às normas e aos sentimentos que inspiram a ação humana e pautam a organização das sociedades. Numerosas são as questões cujo tratamento exige que examinemos conjuntamente essas duas grandes vertentes da realidade, considerando as relações que estabelecem entre si. Nós nos deparamos, de mais em mais, com a evidência de que, para compreender a marcha do mundo e resolver os problemas aos quais somos confrontados, é indispensável integrar em uma mesma análise as molas e rodagens da mecânica que governa o mundo em suas manifestações materiais e a alquimia complexa das ideias, valores, desejos e sonhos que molda a forma como nós o consideramos, interpretamos suas injunções e tentamos agir sobre ele para submetê-lo às nossas intenções.

Avançar na compreensão dessa realidade híbrida implica ir muito além das interpretações sugeridas pelas opiniões do senso comum (Bachelard, 1983), a que somos amiúde tentados a nos contentar quando pretendemos integrar o "fator humano" na análise desses problemas. É preciso produzir um novo tipo de conhecimento científico, por meio de uma pesquisa concebida de modo a articular as contribuições de diferentes disciplinas, as quais possuem ferramentas teóricas e metodológicas que permitem examinar essa realidade em suas dimensões tanto material e como imaterial. A fim de selecionar um exemplo, entre muitos outros, são colaborações desse tipo que permitiram entender 
melhor a dinâmica da epidemia da Aids no mundo, ultrapassando principalmente ideias concebidas sobre a sexualidade e reunindo em campos de pesquisa comum antropólogos, sociólogos, epidemiologistas, biólogos e médicos (Raynaut, 1996; 1997).

É nessa aproximação, numa perspectiva de pesquisa comum, de disciplinas que se ignoraram durante tanto tempo que reside, sem dúvida, um dos maiores desafios da prática interdisciplinar e seu maior potencial de inovação. A invenção de outra prática científica se faz necessária. Uma ciência integrada à vida cotidiana, que leve em conta as interrogações que partem da experiência vivida, totalmente estranha, portanto, ao recorte disciplinar $^{13}$. No entanto, considerar esses aspectos não pode significar a perda de rigor nos procedimentos da pesquisa. Essa ciência não pode levar a demanda social ao pé da letra, mas transformá-la em uma problemática científica que lança luz sobre as múltiplas facetas do problema escolhido. Deve também formular hipóteses as quais diferentes disciplinas terão de submeter seus próprios processos de validação e traçar um caminho de articulação de seus resultados, capaz de levar a um modelo integrado de interpretação da realidade assim analisada.

O sucesso da colaboração entre as ciências sociais e as ciências da matéria pressupõe uma condição fundamental: o reconhecimento recíproco da pertinência das questões tratadas por cada uma delas, inclusive para responder a perguntas que cada uma se coloca por conta própria.

As ciências humanas devem reconhecer a natureza profundamente ambivalente do ser humano e das sociedades, sua dupla natureza, ao mesmo tempo imaterial e profundamente arraigada na matéria - o que Godelier chama de "a parte não social do social" (Godelier, 1984). Dar conta da existência e da história humana tanto em escala individual quanto coletiva somente é possível a partir dessa dualidade, pois o universo imaterial de representações, símbolos, crenças, sabores, normas sociais e emoções que constitui a própria matéria sobre a qual trabalham as ciências humanas é estreitamente ligado a uma base física que é, ao mesmo tempo, condição de sua existência e um objeto para o pensamento e para os afetos.

Entretanto, as ciências físicas e naturais devem admitir que as produções do espírito humano não são meras fantasias que servem para ornar ou mascarar uma realidade mais essencial e determinante que seria a da matéria. Devem reconhecer que essas produções fazem tanto parte da realidade quanto os fatos tangíveis que merecem sua atenção; que elas obedecem a uma lógica interna, a relações de causalidade que lhes são próprias, sem que seja preciso buscar sua origem primeira em determinações de ordem material. Ideias são capazes de engendrar outras ideias; as relações sociais criam condições (tensões, conflitos, solidariedade, construção de identidades etc.) que desembocam na emergência de novas relações sociais; os saberes tornam possível a constituição de outros saberes. As ciências exatas têm de aceitar que, em um número crescente de questionamentos que lhes são dirigidos, essa lógica própria dos fatos imateriais é inseparável de seu objeto de estudo e também que ela desempenha um papel determinante não apenas na dinâmica das sociedades humanas, mas também nos sistemas físicos e naturais que elas estudam.

A pesquisa interdisciplinar, quando conduzida nesse espírito, implica um trabalho de equipe que

\footnotetext{
${ }^{13}$ Essa é a pesquisa de "modo 2", como a descrevem e analisam Nowotny et al. (2001).
} 
reúne especialistas com um domínio profundo de sua respectiva área de estudo, capazes de trazer a mais eficiente e rigorosa contribuição para a exploração do campo considerado no âmbito do trabalho coletivo. Formar essas equipes não é fácil, uma vez que as formações especializadas dos pesquisadores, seja qual for a disciplina considerada, preparou-lhes muito pouco para sair dos contornos definidos de sua especialidade científica. Estamos então, aqui também, diante de um desafio pedagógico. Ele é diferente, porém, daquele que destacamos quando, como vimos anteriormente, procura-se formar "mentes esclarecidas" que saibam ter uma visão global ao abordar uma questão teórica ou prática e, por isso, consigam integrar em sua reflexão um amplo leque de conhecimentos advindos do estado atual da pesquisa. Trata-se, no caso evocado aqui, de aprender um procedimento de produção de conhecimentos baseado em um trabalho de equipe que assegura a articulação das abordagens teóricas, dos questionamentos e métodos de trabalho de parceiros vindos de horizontes científicos distintos. O objetivo não é fazer com que a antropologia integre em sua reflexão sobre a saúde saberes da medicina ou que o botânico leve em conta, ao analisar o ecossistema que ele estuda, o que já sabemos sobre os usos que dele fazem as populações humanas que o exploram. O que é preciso ensinar a esses diferentes pesquisadores é a ter consciência dos limites de sua própria abordagem, bem como a conhecer e compreender o modo de trabalho dos outros e a colaborar com eles na elaboração de uma problemática comum. Precisam, em seguida, saber integrar em seu próprio campo de reflexão e de investigação algumas questões formuladas por essa problemática, ajustando seus métodos de coleta de dados com os de outros pesquisadores da equipe, a fim de que os resultados obtidos por todos possam, no final do percurso, serem aproximados e cruzados. Por fim, é necessário que saibam contribuir com a elaboração de uma síntese que coloque em sinergia os saberes particulares trazidos por cada um. Tal itinerário de formação, assim como um exemplo concreto de um programa de pesquisa concebido nesse espírito, foi detalhado em outros trabalhos (Raynaut \& Zanoni, 2011; Raynaut, 2015b). Aqui me deterei a destacar que essa prática de interdisciplinaridade não pode ser equiparada às duas outras visadas que examinamos anteriormente. O desafio que ela se propõe é maior, pois se baseia em uma contradição. Por um lado, ela não questiona a divisão em disciplinas, mas reconhece sua validade com o anseio de tirar partido das competências advindas da especialização. Por outro, ela afirma que devemos e podemos ultrapassar essas divisões a fim de inovar na produção de novos conhecimentos, dando conta de compreender, assim, a complexidade e o caráter híbrido da realidade que se coloca diante de nossos olhos.

Esse desafio pode desencadear abalos significativos quando se pretende questionar o âmago de uma clivagem que divide profundamente nossa prática científica, e fazer colaborar, em pé de igualdade, disciplinas que se debruçam sobre dimensões da realidade diferentes na sua essência. Não mais se trata aqui de empréstimos que conduzem a um uso aproximado e metafórico de conceitos que migram entre esses dois grandes domínios - como ocorre em uma abordagem mais especulativa da interdisciplinaridade. O objetivo é integrar objetos materiais e imateriais em um percurso de pesquisa combinado que, respeitando tanto as exigências de rigor próprias às ciências humanas como às que lidam com a matéria, visa a articulá-las em um modelo integrado de compreensão. Almeja-se aqui 
uma verdadeira revolução epistemológica, como também uma revisão profunda dos paradigmas que estruturaram até então nosso pensamento científico.

\section{Conclusão}

A formulação da ideia de interdisciplinaridade é frequentemente marcada por certa imprecisão tanto no que diz respeito às próprias disciplinas envolvidas como no que envolve as relações que estabelecem entre si e o modo como se almeja reformular esses laços para responder aos desafios atuais da produção de conhecimento. A diversidade de abordagens interdisciplinares e suas concepções não é, de forma alguma, um problema em si. Ela pode mesmo se configurar como uma riqueza. Todavia, somente se uma distinção clara for estabelecida entre essas diferentes interpretações: clareza indispensável para a coerência dos projetos elaborados sob a égide dessa noção e para a pertinência das estratégias pelas quais nos esforçamos para lhe dar uma expressão institucional eficaz e duradoura.

O primeiro risco é dar à noção de interdisciplinaridade uma acepção tão ampla a ponto de não a distinguir dos movimentos espontâneos que, ao longo do tempo, marcaram o cenário científico e que fazem parte da própria história das disciplinas: circulação de conceitos e métodos, integrações recíprocas de elementos de informação, reflexão crítica sobre os modelos de interpretação desenvolvidos por cada disciplina e convergências em torno de objetos de estudo comuns. Sob efeito dessa dinâmica, cisões não pararam de ocorrer no âmago dos campos disciplinares, assim como aproximações entre abordagens científicas que tinham se afastado da ortodoxia de suas respectivas disciplinas. Tal evolução é inerente ao próprio exercício da reflexão científica, cuja força inovadora se baseia justamente no questionamento permanente das certezas estabelecidas. Podemos certamente considerar que essas transgressões de fronteiras, essas pontes lançadas de uma disciplina a outra, constituem certa forma de interdisciplinaridade, uma vez que estabelecem uma relação entre as disciplinas. Podemos, porém, perguntar o que se ganha em enquadrar, desse modo, em uma rubrica comum, movimentos intelectuais cuja fertilidade advém de seu caráter livre e espontâneo. Ao tentar domesticá-los, prendendo-os em moldes institucionais pré-estabelecidos, não corremos o risco de os tornar estéreis ao invés de estimulá-los? Em contrapartida, como evidentemente essas abordagens inovadoras podem entrar em conflito com forças conformistas que vigiam a integridade das disciplinas, é preciso estar atento para que os processos de avaliação dos projetos, as publicações, as carreiras, atreladas ao julgamento dos pares, não penalizem as iniciativas que podem parecer uma ameaça para a ortodoxia disciplinar. Devem existir, no cerne das universidades, nos organismos de pesquisa e nos comitês editoriais, instâncias cuja função é acompanhar e dar apoio institucional às atividades científicas, aos procedimentos e aos espaços favoráveis à inovação, de modo a fazer um contrapeso às forças que trabalham para manter a homogeneidade interna nos campos disciplinares.

Sem dúvida, ganharíamos em clareza e em eficiência ao reservar o termo interdisciplinaridade às perspectivas que, ao invés de colocarem em questão a divisão em disciplinas, valorizam, ao contrário, o embate de pontos de vista decorrentes dessa divisão. O questionamento das fronteiras disciplinares, a lembrança de seu caráter de artifício metodológico e a exploração de sua porosidade constituem, sem dúvida, uma problemática pertinente e ambiciosa. Entretanto, ela não pode ser confundida com o obje- 
tivo mais imediato de explorar a natureza complexa e híbrida de uma realidade a ser compreendida. $\mathrm{Ou}$ com o anseio de resolver um problema valendo-se da variedade de ferramentas conceituais e metodológicas que a multiplicidade das disciplinas nos coloca à disposição, visando à aproximação e articulação de elementos de conhecimentos heterogêneos que elas fornecem. Pode ocorrer que, no final do processo, essas aproximações e colaborações desemboquem em uma recomposição duradoura dos campos científicos, mas isso seria a consequência de uma prática interdisciplinar e não seu ponto de partida.

Mesmo quando se adota essa definição mais restrita de interdisciplinaridade, o leque de interpretações dessa noção permanece amplo, bem como os objetivos ao serviço dos quais ela é aplicada. Ainda aqui, explicitar as diferenças é indispensável para manter a pertinência e a coerência dos projetos implantados. As nuances são inumeráveis, mas nós tentamos agrupá-los em três grandes categorias. Cada uma delas corresponde a uma abordagem diferente de cooperação entre as disciplinas, com objetivos diferentes, participantes com perfis distintos e estratégias de formação que não podem se confundir.

Destacaremos, primeiramente, uma interdisciplinaridade exercida a partir de conhecimentos já produzidos pelas diferentes especialidades científicas, a qual se propõe a ultrapassar a imagem fragmentada e caleidoscópica da realidade que elas nos fornecem quando as recebemos de forma dispersa. O objetivo é, portanto, a integração e a síntese. Essa abordagem visa à formação de pensadores que não se deixam emprisionar na estreiteza do espaço intelectual de um saber especializado, mas sim são capazes de tecer laços entre conhecimentos advindos de diferentes horizontes científicos. Ela inspira um projeto pedagógico com numerosos desdobramentos desde o ensino básico, com o propósito de formar cidadãos responsáveis, até o ensino universitário de mais alto nível que se volta para a formação de generalistas, de "espíritos esclarecidos" capazes de lidar com problemas complexos de natureza teórica e prática. Nessa perspectiva, a formação em questão frisa, antes de mais nada, à abertura da mente e à capacidade de síntese.

Uma outra abordagem interdisciplinar diz respeito aos profissionais cuja atividade implica colaboração constante de especialistas que têm competências diferentes das suas. Trata-se de uma abordagem operacional voltada à realização de objetivos concretos que só podem ser atingidos a partir da cooperação de profissionais com pleno domínio de suas habilidades. Nesse caso, a prioridade pedagógica se concentra na capacidade de escuta, no trabalho de equipe e na assimilação de métodos de trabalho baseados na interdependência de tarefas. Essas práticas são antigas como as grandes realizações técnicas, cujo sucesso se baseia na cooperação de diferentes segmentos profissionais. A aprendizagem se deu, durante muito tempo, no curso da ação, sem que a ideia de interdisciplinaridade fosse sequer evocada. Porém, é de mais em mais necessário atualmente que essa instrução seja integrada na própria formação profissional. Essa necessidade se dá por conta da complexidade crescente das operações técnicas, mas também, e sobretudo, por causa da imbricação cada vez maior entre fatores de natureza heterogênea na gênese dos problemas que devem ser resolvidos. Dimensões técnicas, econômicas, sociais, psicológicas, políticas, culturais e éticas são, entretanto, estreitamente ligadas quando estão em questão realizações que dizem respeito à energia, ao urbanismo, à saúde ou ao meio ambiente. Trabalhar com parceiros advindos de horizontes intelectuais 
e profissionais tão distintos não é natural, mas sim algo que deve ser aprendido. Esse é o desafio a que, ainda por cima, devem se confrontar os cursos de ensino que formam especialistas altamente qualificados em uma área específica, mas que são igualmente capazes de trabalhar com pessoas cujas preocupações e métodos lhes são estrangeiros.

Por fim, identificamos outra abordagem de interdisciplinaridade que tem como propósito a produção de novos conhecimentos sobre temáticas cuja complexidade exige a formação de programas de pesquisa que associam cientistas advindos de uma ampla gama de campos disciplinares. O objetivo, nesse caso, não é cruzar saberes já adquiridos nem coordenar intervenções voltadas à realização de tarefas previamente estipuladas. Trata-se de se engajar em uma nova aventura intelectual, de explorar o real sobre terrenos ainda não desbravados. Essa interdisciplinaridade não pode ser solitária. Exige um trabalho de equipe em que se reúnem pesquisadores com absoluto domínio nas competências de suas respectivas disciplinas. Isso pressupõe a convergência de todos em torno de uma problemática comum que dê conta das múltiplas facetas do problema tratado, a qual permita, ao mesmo tempo, que cada um possa contribuir no trabalho coletivo com os recursos de sua própria disciplina. Está em jogo todo um processo de compreensão mútua, de negociações e de conciliações envolvendo tanto dimensões conceituais quanto aspectos metodológicos. Ou seja, exige não apenas uma disposição de espírito, mas também habilidades e até mesmo um aparato metodológico adequado que permite a síntese de informações heterogêneas dentro de um modelo de compreensão e de explicação que as ponha em relação. Essas competências não se improvisam, seja qual for o grau de excelência do pesquisador em sua própria especialidade. Inúmeras experiências mostraram que não basta reunir os melhores especialistas para instaurar uma dinâmica de trocas e de colaboração. Menos que qualquer outra, essa prática de interdisciplinaridade não se dá imediatamente; ela se constrói metodicamente. Os obstáculos são particularmente difíceis de superar quando, como ocorre de forma mais frequente hoje em dia, os temas explorados demandam a colaboração de cientistas cujos universos de referência são distintos entre si: as ciências humanas, de um lado; $\mathrm{e}$ as ciências que lidam com as dimensões materiais da realidade, de outro. Não podemos nos contentar com um jogo de analogias e de metáforas com as quais pensadores dos dois lados tentam estabelecer correspondências entre esses dois campos de pensamento. O desafio é obter modelos explicativos apoiados em um trabalho empírico que permita lançar luz sobre as interações entre os fatores advindos de cada um desses domínios. Para tal, métodos de pesquisa inovadores devem ser experimentados e, em seguida, transmitidos aos pesquisadores com o propósito de ultrapassar sua formação especializada para se engajarem nesse novo modo de trabalho coletivo.

Sob o termo geral de interdisciplinaridade, estão em questão projetos científicos e pedagógicos muito diferentes. Tentei aqui destacar algumas linhas de força que permitem organizar essa diversidade. Sem dúvida, é preciso ir mais longe e ser mais profundo nesse esforço de diferenciação. Entretanto, é certo, desde já, que o debate permanecerá estagnado enquanto não se tornarem mais claros os princípios, os objetivos, os métodos, muitas vezes díspares, ao redor dos quais essas posições se organizam. É a condição necessária para que possamos sair da confusão que frequentemente ainda reina quando falamos em interdisciplinaridade; condi- 
ção também para conseguir ultrapassar as falsas interpretações, preconceitos e resistências que a impedem de ser integrada de modo duradouro e incontestável nas instituições. A interdisciplinaridade, enquanto abordagem de produção e transmissão de conhecimento, tem ainda que encontrar seu lugar em muitos estabelecimentos de ensino e pesquisa. Um lugar que não a torna antagônica ao percurso disciplinar clássico, mas faz dela o desdobramento, o complemento desse percurso uma vez que este conserva sua pertinência própria e prossegue na sua própria lógica de evolução e recomposição.

\section{Referências}

Apostel L. Interdisciplinarity: Problems of Teaching and Research in Universities. OCDE: Paris, 1972.

Bachelard, G. La formation de l'esprit scientifique. Paris: Librairie Philosophique J. Vrin, 1983.

Becher, T.; Trowler, P. R. Academic tribes and territories. Intellectual inquiries and the Cultures of Disciplines. Buckingham: Open University Press, 1989.

Bevilacqua, L. Sobre a Universidade no Brasil na Era do Choque Cultural - A Formação para Tecnologia. In: Gauthier, F. O. et al. (Org.). Interdisciplinaridade. Teoria e Prática. Florianópolis: UFSC/EGC, 2014, p. 15-36.

Bourdieu, P. Postface. In: Architecture gothique et pensée scolastique, Paris: Éditions de Minuit, 1967, p. 135-167.

Bouveresse, J. Prodiges et vertiges de l'analogie. Paris: Éditions Raisons d'Agir, 1999.

Christin, O. (Dir.) Dictionnaire des concepts nomades en Sciences Humaines. Paris: Métailié, 2010.

Damish, H. L'origine de la perspective. Paris: Flammarion, 1993.

Delhaye, P. Le défi de l'interdisciplinarité dans l'acte de formation au travail social. Pensée Plurielle, Quelques approches de la nouvelle gouvernance (2). Charleroi, Louvain, Lille: De Boeck Supérieur, 2014, p. 111-120.

Duby, G. Le temps des cathédrales - L'Art et la Société. Paris: Gallimard, 1976.

Durel, H. Bacon, père de l'Encyclopédie. In: Groult, M. (Ed.). Encyclopédie, la création des disciplines. Paris: CNRS, 2003.
Frodeman, R.; Klein, J. T.; Mitcham, C. (Eds.). The Oxford Handbook of interdisciplinarity. Oxford: Oxford University Press, 2010.

Fuller, S. L'interdisciplinarité. La fin de l'image héroïque dans la marche des idées. In: Origgi, G.; Darbellay, F. Repenser l'interdisciplinarité. Genève: Édition Slatkine, 2010, p. 57-66.

Godelier M. Rationalité et irrationalité en économie. Paris: Maspero, 1968.

Godelier, M. L'idéel et le matériel. Pensées, économies, sociétés. Paris: Fayard, 1984.

Grabar, A. Les origines de l'esthétique médiévale. Paris: Macula, 1992.

Hacking, I. Disciplinaire et satisfait, In: Origgi, G.; Darbellay, F. Repenser l'interdisciplinarité. Genève: Édition Slatkine, 2010, p. 77-84.

Holbrook, J. B. Peer Review. In: Frodeman, R.; Klein, J. T.; Mitcham, C. (Eds.). The Oxford Handbook of interdisciplinarity, Oxford University Press, Oxford, 2010, p. 321-332.

Klein J. T. Crossing Boundaries. Knowledge, disciplinarities and interdisciplinarities. The University Press of Virginia, Charlottesville, 1996.

Kremer-Marietti, A. De l'unité de la science à la science unifiée: de Comte à Neurath. In: Petit, A. (Dir.). Auguste Comte, trajectoires positivistes 1798-1998. Paris: L'Harmattan, 2003.

Lenoir, Y. Formation à l'enseignement et interdisciplinarité: Un mythe ou une exigence? Dépasser l'interdisciplinarité et 
penser circumdisciplinarité. European Journal of Teacher Education, 23(3), 289-298, 2000.

Lenoir, Y.; Larose, F.; Dirand, J.-M. Formation professionnelle et interdisciplinarité: quelle place pour les savoirs disciplinaires? In: Fraysse, B. (Dir.). Professionnalisation des élèves ingénieurs. Paris: Éditions L'Harmattan, 2006, p. 13-35.

Lenoir, Y.; Sauve, L. L'interdisciplinarité et la formation à l'enseignement primaire et secondaire: quelle interdisciplinarité pour quelle formation? Revue des sciences de l'éducation, XXIV(1), 3-29, 1998.

Neurath, O.; Carnap, R.; Morris, C. International Encyclopedia of Unified Science, The University of Chicago Press, 1938.

Nowotny, H.; Scott, P.; Gibbons, M. Re-Thinking Science: Knowledge and the Public in an Age of Uncertainty. Cambridge: Polity Press, 2001.

OCDE. The University and the Community. The Problems of Changing Relationships. Paris: OCDE, 1982

Origgi, G. ; Darbellay, F. Repenser l'interdisciplinarité. Genève: Édition Slatkine, 2008

Panofsky, E. La perspective comme forme symbolique. Paris: Éditions de Minuit, 1975.

Parain, Ch. Outils, Ethnies et Développement historique. Paris: Editions sociales, 1979.

Pestre, D. L'évolution des champs de savoir, interdisciplinarité et valorisation. In: Origgi, G.; Darbellay, F. Repenser l'interdisciplinarité. Genève: Édition Slatkine, 2008, p. 39-50.

Philippi Jr., A.; Fernandes, V. Práticas da interdisciplinaridade no ensino e pesquisa. Barueri: Manole, 2015.

Philippi Jr., A.; Silva Neto, A. J. Interdisciplinaridade em Ciência, Tecnologia \& Inovação. Barueri: Manole, 2011.

Raynaut, C. Quelles questions pour la discipline, quelle collaboration avec la médecine? In: Benoist, J.; Desclaux, A. (Eds.). Anthropologie et sida. Bilan et perspective. Paris: Karthala, 1996, p. 31-56.
Raynaut, C. L'Afrique et le sida: questions à l'Anthropologie, l'Anthropologie en question. Sciences Sociales et Santé, 15(2), 9-38, 1997.

Raynaut, C. Dicotomia entre ser humano e natureza: paradigma fundador do pensamento científico. In: Philippi Jr., A.; Fernandes, V. Práticas da interdisciplinaridade no ensino e pesquisa. Barueri: Manole, 2015a, p. 3-35.

Raynaut, C. Interdisciplinaridade na pesquisa: lições de uma experiência concreta. In: Philippi Jr., A.; Fernandes, V. Práticas da interdisciplinaridade no ensino e pesquisa. Barueri: Manole, 2015b, p. 523-550.

Raynaut, C.; Zanoni. M. Reflexões sobre princípios de una prática interdisciplinar na pesquisa e no ensino superior. In: Philippi Jr., A.; Silva Neto, A. J. Interdisciplinaridade em Ciência, Tecnologia \& Inovação, Barueri: Manole, 2011, p.143-208.

Repko A. F. Interdisciplinary research. Process and Theory. London, Sage, 2008.

Sokal, A.; Bricmont, J. Impostures intellectuelles. Paris: Éditions Odile Jacob, 1997.

Stengers, I. (Dir.). D'une science à l'autre: des concepts nomades. Paris: Le Seuil, 1987.

Vérin, H. Autour du mot Ingénieur. L'identité de "l'ingénieur". Quelques repères historiques. Recherche et formation, n² 29, Lyon: ENS, 1998, p. 11-20.

Vinck, D.; Robles Belmont, E. Convergence dans les nanosciences et les nanotechnologies. Le cas des micro et nanosystèmes. In: Miège, B.; Vinck, D. (Eds.). Les Masques de la convergence. Enquêtes sur sciences, industries et aménagements. Paris: Editions des Archives Contemporaines, 2012.

Weber C. I. et al. A contribuição da Interdisciplinaridade par Superação da Fragmentação na Formação Acadêmica. In: Gauthier, F. O. et al. (Org.). Interdisciplinaridade. Teoria e Prática. Florianópolis: UFSC/EGC, 2014, p. 37-54.

Weingart, P. A short history of knowledge formations. In: Frodeman, R.; Klein, J. T.; Mitcham, C. (Eds.). The Oxford Handbook of interdisciplinarity, Oxford University Press, Oxford, 2010, p. 3-14. 